\title{
INTENSITY MEASURE SELECTION FOR VULNERABILITY STUDIES OF BUILDING CLASSES
}

\author{
A.K. Kazantzi ${ }^{1 *}$, D. Vamvatsikos ${ }^{2}$ \\ ${ }^{1}$ J.B. ATE, Construction Company, Herakleion, Crete, Greece. \\ ${ }^{2}$ School of Civil Engineering, National Technical University of Athens, Athens, Greece.
}

\begin{abstract}
The selection of a scalar Intensity Measure (IM) for performing analytical vulnerability (loss) assessment across a building class is addressed. We investigate the ability of several IM choices to downgrade the effect of seismological parameters (sufficiency) as well as reduce the record-to-record variability (efficiency) for both highrise and lowrise sets of "index" buildings. These characteristics are explored in unprecedented detail, employing comparisons and statistical significance testing at given levels of local engineering demand parameters (story drift ratios and peak floor accelerations) that relate to losses, instead of global variables such as the maximum interstory drift. Thus, a detailed limit-state-specific view is offered for the suitability of different scalar IMs for loss assessment. As expected, typical single-period spectral values are found to introduce unwanted bias at high levels of scaling, both for a single as well as a class of buildings. On the other hand, the geometric mean of the spectral acceleration values estimated at several periods between the classaverage second-mode and an elongated class-average first-mode period offers a practical choice that significantly reduces the spectral-shape bias without requiring the development of new ground motion prediction equations. Given that record selection remains a site-and building-specific process, such an improved IM can help achieve reliable estimates for building portfolios, as well as single structures, at no additional cost.
\end{abstract}

Keywords: intensity measure; vulnerability; building class; incremental dynamic analysis

\section{INTRODUCTION}

The analytical estimation of seismic losses involves combining the seismic hazard determined by seismologists with the results of structural and loss analyses evaluated by structural engineers (e.g. [1]). In formal terms, this is the integration of a site's seismic hazard curve with the so-called vulnerability function, i.e., a function that conveys the distribution of loss (repair cost, casualties, downtime) given the level of seismic intensity for a given structure or class of structures. This is the basis of the conditional approach $[2,3]$ where the single point of contact between seismology and structural engineering is the Intensity Measure (IM). The IM is essentially an interface variable that efficiently separates the two disciplines: Seismologists need to estimate the IM's statistical properties via probabilistic seismic hazard analysis (PSHA, [4]), while engineers can economize by assessing structural response and losses conditioned on the level of the IM, rather than a combination of magnitude, distance and other seismological parameters. To achieve this desirable decoupling, the IM needs to be (a) practical, (b) efficient and (c) sufficient with respect to the underlying characteristics of site and source [5].

Practicality necessitates the use of IMs for which Ground Motion Prediction Equations (GMPEs, also known as attenuation relationships) are available. This essentially restricts us to the realm of peak ground acceleration/velocity/displacement and (pseudo) spectral

\footnotetext{
*Corresponding author: kazantzi@mail.ntua.gr
} 
acceleration values, which is where most seismological research is being focused. Efficiency means that structural response, measured by appropriate Engineering Demand Parameters (EDPs), should exhibit a low record-to-record variability at any given level of the IM. This enables the evaluation of the conditional EDP distribution with a small number of timehistory analyses without incurring considerable estimation errors. The gain is even higher when assessing the seismic vulnerability for a building class, since the analysis process, which involves several nonlinear dynamic analyses, needs to be repeated for every representative "index" building within the class.

It should be noted that within a risk assessment framework, such as the one described by the Cornell-Krawinkler equation [6] adopted by the Pacific Earthquake Engineering Research (PEER) Center, this reduction in response dispersion gained by a more efficient IM, does not reduce the overall risk variability. A different IM is simply a different partitioning of the sample space for applying the total probability theorem implied by Cornell and Krawinkler [6]. Thus, part of the variability is simply shifted to a different level within the risk assessment, and in particular to the seismic hazard curve definition. A more efficient IM is invariably more structure specific and thus incurs higher dispersions when trying to define an appropriate ground motion prediction equation (GMPE). In other words, no matter the adopted IM, as long as sufficiency is maintained we should end up with the same overall variability at the end of the risk assessment, i.e., after convolving the vulnerability with the hazard. This is best understood if the "perfect IM" is employed, i.e., the IM is set to be the EDP of interest for the structure. Then there is absolutely no dispersion or bias in the analysis results, as IM given EDP is essentially a trivial relationship. On the other hand, defining an appropriate GMPE would have us running thousands of nonlinear ground motion analyses of the entire structure for different values of magnitude, distance etc and the entire variability will enter the GMPE definition. However, there is a significant advantage associated with lowering the dispersion at the response analysis estimation step and recovering it later on in the process, at the probabilistic hazard analysis step: A vastly reduced cost of analysis.

On the other side, the sufficiency requirement stipulates that the IM can "cover" the effect of any important seismological parameter, thus removing any bias from considering, e.g. ground motions of different magnitudes, distances, fault rupture mechanisms or epsilons (see [7]). Epsilon " $\varepsilon$ ", represents the number of standard deviations that a certain ground motion quantity (e.g. logarithmic spectral acceleration) is away from the average value estimated for records of the same general characteristics by a GMPE (e.g., the Abrahamson and Silva [8] expressions employed herein). While a user with abundant computational resources might be able to tolerate an inefficient IM, sufficiency still remains a sine qua non condition. An insufficient IM will leave the EDP response sensitive to such seismological parameters. Thus it can let unwanted bias to creep into vulnerability estimates wherever the ground motion characteristics do not match the source and site requirements for the building and IM level under consideration. This is actually the case of vulnerability assessment studies undertaken for a class of buildings within a wide geographic region, where ground motion selection techniques, e.g. the conditional mean spectrum [9], or incorporating near source directivity, are not fully applicable to the broad distribution of site hazard conditions encountered for each building.

Finally, it should be mentioned that apart from the efficiency, sufficiency and practicality, there is also the issue of predictability, i.e. the ability to accurately predict an IM through GMPEs [13]. In some cases this may be an important property of a robust IM. However, in the present study this is not an issue since the investigated IMs were based on elastic spectral acceleration quantities for which accurate GMPEs exist. This however, may not be the case for other IMs, such as the Arias Intensity. 
Together with the selection of IM, comes the selection and scaling of ground motions for time-history analysis. Since vulnerability curves are needed for a large range of intensities, a structure needs to be subjected to a wide range of IM values that will force it to show its full range of response. Due to limitations in the catalogue of ground motion recordings, it is often desirable to be able to modify (i.e. scale) a record to display the desired IM level. Generating artificial accelerograms is another potential approach, but it is not recommended for general use at this point, since it may offer biased or less variable structural demands compared to natural records [10]. A sufficient IM theoretically allows unrestricted scaling of ground motions. In reality, though, no single IM is perfect. Therefore, exercising at least a minimum of care in selecting ground motions is advised. For instance, Katsanos and Sextos [11] and Jayaram et al. [12] proposed different algorithms for performing a structure-specific ground motion selection. Such approaches however are not applicable to a class of buildings where the structural properties may vary substantially. In general, our recommendation for class vulnerability assessment is to use the best possible IM that will allow a wide range of scaling, plus a suite of relatively strong ground motion records recorded on firm soil (e.g. NEHRP classes $\mathrm{A}$ to $\mathrm{D})$. Whenever sufficient information exists about the dominant seismic mechanism or soil site in the region for which the vulnerability curve is developed (e.g. crustal earthquakes in California or soft soil in Mexico City), it may help an experienced analyst in better choosing what records to use.

On account of the above, this study will explore the IM selection issue from the perspective of satisfying the aforementioned requirements for a building class. In other words, the selected IM should be efficient and sufficient for the whole set of index buildings that form the class, rather than for each index building alone. The test bed is a set of seven highrise reinforced-concrete moment-resisting frames (RCMRFs) and a set of six lowrise steel moment-resisting frames (SMRFs) that were built to modern design requirements for highseismicity regions in the US and cover a wide range of structural periods. For assessing the structural response, Incremental Dynamic Analysis (IDA) [14] is employed. By undertaking an extensive comparison study for a range of IMs evaluated at several period bands, we will attempt to provide a simple rule for defining a common efficient and sufficient IM, suitable for analytical vulnerability studies that involve an entire building class. While no loss assessment will be performed per se, this is not necessary for our purposes: We need only examine the connection of each IM with the primary EDPs that constitute the basis of loss assessment.

\section{INCREMENTAL DYNAMIC ANALYSIS FUNDAMENTALS}

For evaluating the seismic performance of the index buildings, IDA [14] is proposed as the benchmark analysis methodology. IDA is a powerful tool of structural analysis that involves performing a series of nonlinear time-history analyses for a suite of ground motion records, the latter scaled at increasing intensity levels. To define the IDA curves, two scalars are needed, these being an IM to represent the severity of the seismic input and an EDP to monitor the structural response. For the present study, a number of different IMs were used for illustrating their efficiency and sufficiency, whereas two classes of EDPs were employed: The peak interstory drift ratio (IDR) at each story and the peak floor acceleration (PFA) at each floor. These two EDP types are deemed to be adequate for assessing the structural, non structural and content losses [15].

The ground motion records needed for the IDAs come from the far-field record set of FEMA P695 [16], which contains 22 natural ground motion records with two components each (i.e. 44 individual components). These ordinary records were selected from the PEER NGA database [17] and were recorded on firm soil sites (NEHRP class C or D) without having any discernible near-source pulse signal. Furthermore, no more than two records were 
considered from any earthquake event to prevent event bias. Figure 1 illustrates the response spectra of the aforementioned far-field record set, along with the $50 \%$ and the $84 \%$ fractile spectra.

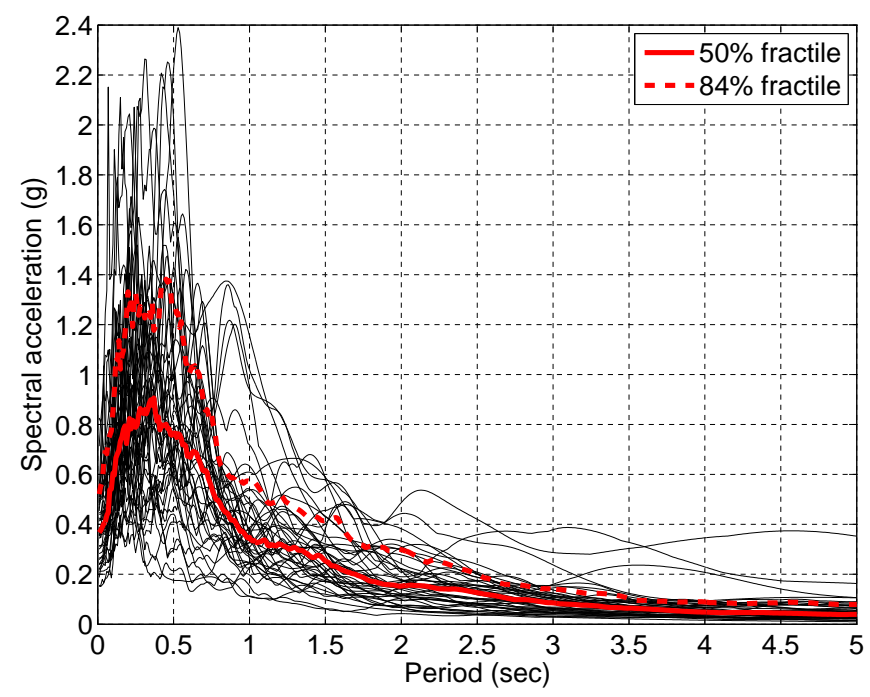

Figure 1. (Pseudo-)Acceleration response spectra of the far-field FEMA P695 records (5\% damping) along with their $50 \%$ and the $84 \%$ fractile values.

\section{IM SELECTION BACKGROUND THEORY}

Being aware of the problem constraints, we will investigate the important issue of selecting a common IM. Despite the fact that several past studies were focused on the IM choice, to the authors' knowledge none of them has so far explicitly addressed the problem from a building class point of view. The best known option for an IM is the $S_{a}(T)$, i.e. the 5\% damped spectral acceleration at the period of interest (usually the structure's first-mode period, $T_{1}$ ). It is relatively efficient, yet it has often been criticized for lack in sufficiency wherever large scale factors (higher than, say 3.0) are employed. This is mainly the case for modern structures that need considerably intense ground motions to experience collapse. It should be noted here that the majority of the ground motion databases contain mostly small to moderate records and hence significant scaling is inevitable for assessing the collapse capacity of well-designed structures (e.g., [18]). On the other hand, this is rarely the case for older and deficient buildings. Furthermore, due to the dependence on the first-mode period, $S_{a}\left(T_{1}\right)$ does not satisfy the prerequisite of a common IM across the building class, so as to uniformly parameterize the IDA results and consequently the vulnerability functions of the index buildings. A simple remedy is to choose a common period $T$ that can be considered representative of the class. Two potential candidates are $S_{a}(1 \mathrm{sec})$, for moderate-to-long period structures, and $S_{a}\left(T_{1 \mathrm{~m}}\right)$, where $T_{1 \mathrm{~m}}$ is the central value (mean or median) of the first-mode periods of all index buildings selected to represent the class. For the case at hand, the mean period was found to be $T_{1 \mathrm{~m}}=2.2 \mathrm{sec}$ for the highrise and $T_{1 \mathrm{~m}}=1.3 \mathrm{sec}$ for the lowrise buildings. $S_{a}(1 \mathrm{sec})$ is an IM that has seen much use in existing vulnerability/fragility studies for highrise buildings but its efficiency is highly questionable.

On account of single buildings, an option that has appeared lately is use of a geometric mean of spectral acceleration values at different periods:

$$
S_{\text {agm }}\left(T_{i}\right)=\left[\prod_{i=1}^{n} S_{a}\left(T_{i}\right)\right]^{1 / n}
$$


This was introduced by Cordova et al. [19] as the geometric mean of two $S_{a}$ components evaluated at two period levels, these being the fundamental period $\left(T_{1}\right)$ and twice the fundamental period $\left(2 T_{1}\right)$. The latter period level was introduced to account for the period elongation associated with the structural damage. This choice was proven to significantly improve both the efficiency and the sufficiency of the estimation, compared to $S_{a}(T)$. It also remains practical, as a GMPE for $S_{a g m}\left(T_{\mathrm{i}}\right)$ is easily estimated from existing $S_{a}(T)$ GMPEs using the correlation of spectral ordinates [19]. Since $S_{\text {agm }}\left(T_{\mathrm{i}}\right)$ offers a considerable extension to the applicability of scaling [20,21], it is for the time-being by far the recommended approach whenever undertaking nonlinear dynamic analysis (e.g., IDA).

More recently, Tsantaki and Adam [22] showed that the improvement achieved by adopting $S_{a g m}\left(T_{\mathrm{i}}\right)$ for the record-to-record variability at collapse may be further increased by espousing an enhanced period range. For the latter, they proposed a simple analytical expression that links the initial period $T_{1}$ to an elongated period for use with Eq. (1). A similar IM was also used by Shakib and Pirizadeh [23] who studied the probabilistic seismic performance of a ten-story steel building at various degrees of vertical irregularity (i.e. setback ratios). The adopted $S_{a g m}\left(T_{\mathrm{i}}\right)$ was evaluated over a period range from $0.5 T_{1}$ to $1.5 T_{1}$ in increments of $0.05 T_{1}$. In order to end up with a common IM for all structural configurations, the mean first-mode period $T_{1}$ of the building set was adopted. A similar scalar IM based on $S_{a}\left(T_{1}\right)$ and a parameter $N_{p}$, defined as the ratio of $S_{a g m}\left(T_{\mathrm{i}}\right)$ over $S_{a}\left(T_{1}\right)$, was also proposed by Bojorquez and Iervolino [24] and was found to have improved efficiency [24, 25].

In view of the aforementioned findings, this study will compare the effectiveness of eight IMs, namely $S_{a}\left(T_{1}\right), S_{a}(1 \mathrm{sec})$ and $S_{a}\left(T_{1 \mathrm{~m}}\right)$ together with five $S_{a g m}\left(T_{\mathrm{i}}\right)$ choices, each employing a different selection of common periods $\left(T_{\mathrm{i}}\right)_{j}, j=1 \ldots 5$ :

a. Five logarithmically-equally-spaced periods $\left(T_{\mathrm{i}}\right)_{1}$ within $\left[T_{2 \mathrm{~m}}, 1.5 \cdot T_{1 \mathrm{~m}}\right]$, where $T_{2 \mathrm{~m}}$ and $T_{1 \mathrm{~m}}$ are the mean $T_{2}$ and $T_{1}$ periods, respectively of the index buildings,

b. Seven logarithmically-equally-spaced periods $\left(T_{\mathrm{i}}\right)_{2}$ within $\left[T_{2 \mathrm{~m}}, T_{1 \mathrm{~m}}\right]$,

c. Five linearly-equally-spaced periods $\left(T_{\mathrm{i}}\right)_{3}$ in $\left[T_{2 \mathrm{~m}}, 1.5 \cdot T_{1 \mathrm{~m}}\right]$,

d. Four periods defined as $\left(T_{\mathrm{i}}\right)_{4}=\left[T_{2 \mathrm{~m}}, \min \left[\left(T_{2 \mathrm{~m}}+T_{1 \mathrm{~m}}\right) / 2,1.5 \cdot T_{2 \mathrm{~m}}\right], T_{1 \mathrm{~m}}, 1.5 \cdot T_{1 \mathrm{~m}}\right]$,

e. Five periods defined as $\left(T_{\mathrm{i}}\right)_{5}=\left[T_{2 \mathrm{~m}}, \min \left[\left(T_{2 \mathrm{~m}}+T_{1 \mathrm{~m}}\right) / 2,1.5 \cdot T_{2 \mathrm{~m}}\right], T_{1 \mathrm{~m}}, 1.5 \cdot T_{1 \mathrm{~m}}, 2 \cdot T_{1 \mathrm{~m}}\right]$

Of the eight IMs, only $S_{a}\left(T_{1}\right)$ cannot be used for class-level vulnerability assessment, as previously mentioned. Yet, it will be examined alongside the others to establish a baseline for comparison with current practice. It should also be noted that, the actual definition of the individual $S_{a}(T)$ components to be employed in the determination of the eight candidate IMs depends on the GMPE used for the hazard [26]. GMPEs may be defined for the arbitrary $S_{a}(T)$ horizontal component or the geometric mean of the two $S_{a}(T)$ horizontal components per recording. The latter is the case for most GMPEs produced lately (e.g., PEER-NGA project) and it is the paradigm that we shall adopt in the examples that follow. Thus, for example, the fifth choice for $S_{a g m}\left(T_{\mathrm{i}}\right)$ above, termed $S_{\text {agm }}\left(T_{\mathrm{i}}\right)_{5}$, becomes a geo-mean combination of 10 different $S_{a}$-values, two for each of the five periods.

\section{BUILDING CLASSES}

The present study considers two building classes. Each is represented by a set of "index" buildings [27] that are appropriately selected to reflect the key features of the class, e.g., structural material, lateral force resisting system, height range, and era of construction. First is a class of highrise reinforced-concrete moment-resisting frames (RCMRFs) and the second consists of lowrise steel moment-resisting frames (SMRFs). Both classes refer to modern structures built to post-1980 seismic design provisions for high-seismicity regions (site class D) in the United States. The main features differentiating the buildings within the class are (a) 
the building height, defined as the number of stories, (b) the design base shear, as this was determined by the code-based value of spectral acceleration at $1 \mathrm{sec}$, termed SD1 in the US codes and (c) the vertical irregularity ratio, defined as the ratio of the first story height to the (constant) height of the upper stories, which was deemed important only for the highrise case. The highrise index set consists of seven RCMRFs with heights ranging from 12 to 20 stories, whereas the lowrise case comprises six SMRFs of 1 to 4 stories. The probability distributions of the building features were based on a set of 263 RCMRFs in California [28] and a set of 3562 SMRFs in Memphis [29], respectively. Specifically for the SD1 distribution, used as a proxy for base shear strength, we used county-level data from the high seismicity zones in the US [30]. The main features of the analyzed frames are summarized in Table 1.

The weights that represent the contribution of each index building to the total sample along with the discrete joint probability mass functions of the highrise class key features (defined by means of a common central point and two "sigma set" points per attribute to establish higher moments) were obtained using the moment-matching sampling technique [31]. On that basis, an initial set of highrise index buildings were selected from a building database developed by Haselton et al. [32] and then they were accordingly modified to accurately match the aforementioned attributes. The key features of the lowrise class were defined by means of a class partitioning methodology [33] and the corresponding representative index buildings were selected from a report issued by the National Institute of Standards and Technology (NIST) on the evaluation of the FEMA P695 methodology [34]. For more details on the definition of the classes and their index buildings, the interested reader should refer to Porter et al. [35].

Table 1. Main features of the index buildings. The indices designating SMRF variants correspond to NIST-GCR 10-917-8 [34] models.

\begin{tabular}{ccccccc}
\hline Class & Index & $\begin{array}{c}\text { Feature } X 1 \\
\text { (No of stories) }\end{array}$ & $\begin{array}{c}\text { Feature } X 2 \\
\text { (code design level) }\end{array}$ & $\begin{array}{c}\text { Feature } X 3 \\
\text { (vertical irregularity) }\end{array}$ & $\begin{array}{c}T_{1} \\
\text { (sec) }\end{array}$ & $\begin{array}{c}T_{2} \\
\text { (sec) }\end{array}$ \\
\hline \hline \multirow{6}{*}{ RC highrise } & No0 & 12 & $0.60 \mathrm{~g}$ & 1.744 & 2.14 & 0.73 \\
frames & No1 & 7 & $0.60 \mathrm{~g}$ & 1.744 & 1.61 & 0.52 \\
& No2 & 20 & $0.60 \mathrm{~g}$ & 1.744 & 2.85 & 0.92 \\
& No3 & 12 & $0.60 \mathrm{~g}$ & 1.150 & 2.02 & 0.69 \\
& No4 & 12 & $0.60 \mathrm{~g}$ & 2.745 & 2.42 & 0.81 \\
& No5 & 12 & $0.26 \mathrm{~g}$ & 1.744 & 2.14 & 0.73 \\
& No6 & 12 & $0.97 \mathrm{~g}$ & 1.744 & 2.14 & 0.73 \\
\hline \hline \multirow{5}{*}{ Steel lowrise } & 1ELF & 1 & $0.60 \mathrm{~g}$ & N/A & 0.70 & N/A \\
frames & 2ELF & 2 & $0.60 \mathrm{~g}$ & N/A & 0.87 & 0.23 \\
& 5ELF & 4 & $0.60 \mathrm{~g}$ & N/A & 1.23 & 0.41 \\
& 6ELF & 2 & $0.20 \mathrm{~g}$ & N/A & 1.54 & N/A \\
& 7ELF & 4 & $0.20 \mathrm{~g}$ & N/A & 1.71 & 0.45 \\
\hline \hline
\end{tabular}

\section{MODELING}

Given that we are dealing with symmetric plan buildings, a 2D centerline idealization was adopted for modeling the Multi-Degree-of-Freedom (MDOF) index structures in the OpenSees [36] analysis platform. The behavior of the structural members was modeled with lumped-plasticity elements having their hinge properties evaluated in the case of the reinforced-concrete members from the empirical equations proposed by Panagiotakos and Fardis [37] and in the case of the steel members by the regression equations suggested by Lignos and Krawinkler [38]. Lumped-plasticity elements as opposed to the more sophisticated distributed-plasticity fiber section elements were a conscious choice in favor of simplicity, speed of computation and improved numerical convergence (especially when approaching 
collapse in the sense of global dynamic instability). Geometric nonlinearities in the form of P$\Delta$ effects were considered. Figure 2 depicts a generic model idealization of the perimeter RCMRFs along with their typical plan view as well as the typical plan view of the perimeter SMRFs.

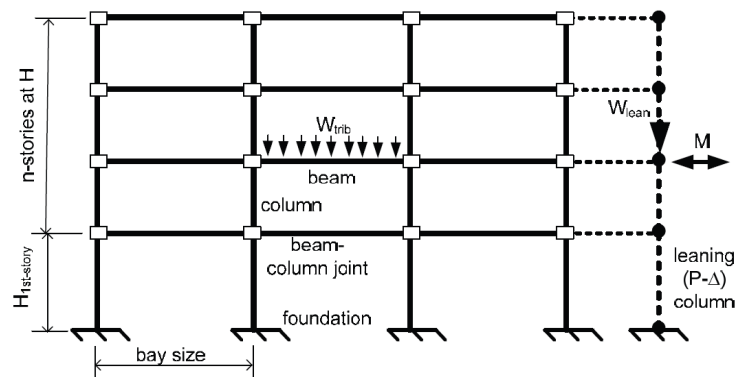

(a)

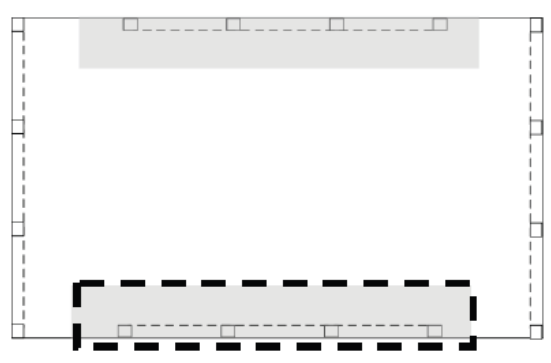

(b)

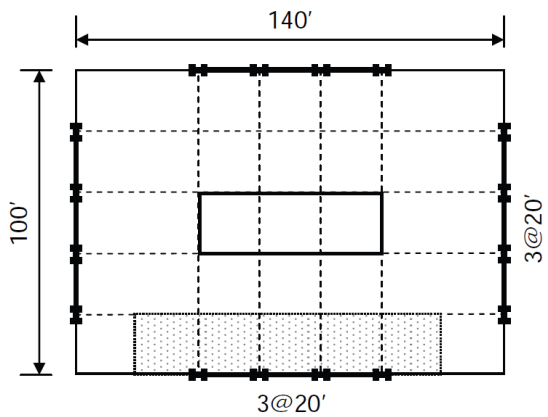

(c)

Figure 2. (a) Generic model idealization of the perimeter RCMRFs (side view), (b) typical plan view of the perimeter RCMRFs (after [16]) and (c) typical plan view of the perimeter

SMRFs (dimensions in ft, after [34]).

\section{IM COMPARISON STUDY}

The efficiency and sufficiency of the different IMs defined in section 3 was tested, in an attempt to identify the optimal IM across the structural response range. The latter is monitored by means of two types of structural response measures, these being the interstory drift ratio (IDR) and the peak floor acceleration (PFA). The proposed methodology differs from similar studies that have appeared in the literature, e.g. [7, 21, 40], in two important aspects, namely (a) using an IM given EDP (IM|EDP) basis and (b) employing all IDR and PFA values at each story or floor, respectively. Working on an IM|EDP basis essentially translates to using "vertical stripes" of points, produced as cross sections of the 44 IDA curves for each index building with a vertical line signifying a given EDP value (see Figure 3).

Thus, for each EDP type and for any number of its values, one may estimate IM "capacity values" required by each corresponding record to reach each prescribed EDP target. This has the obvious advantage of allowing a detailed point-wise assessment of efficiency and sufficiency that can reach all the way up to collapse [20]. On the contrary, past studies have often relied on processing directly EDP values, typically for numerous levels of the IM at the same time, thus being forced to stay away from global collapse where response becomes essentially infinite or undefined. It should be noted here that, in general, the conditional independence of variable $X$ from a seismological characteristic $S$ given a variable $Y$ does not necessarily imply the conditional independence of $\mathrm{Y}$ from $\mathrm{S}$ given $\mathrm{X}$. Still, the situation is quite different when $\mathrm{X}$ and $\mathrm{Y}$ are an IM and an EDP that are so well correlated as to be practically functionally dependent. This is a relationship that is often expressed by a power- 
law function when checking for sufficiency (e.g. [5]). The independence of IM given EDP from a seismological characteristic S, means that the 16/50/84 percentiles of IM|EDP are also independent of S, as being functions of the IM [40]. These values are known to match the 84/50/16 percentiles, respectively, of EDP|IM [41], which also become independent of Y. Assuming, for example, that the distribution of EDP|IM is a lognormal (a typical although unnecessary assumption here), it is thus fully characterized by these percentiles, which means that it does not depend on $\mathrm{S}$ as well. Hence, the close relation of IM and EDP means that checking for sufficiency in terms of IM|EDP yields the same results as checking for EDP|IM. Even more so, one may argue that close to collapse the first formulation, which has been adopted, is advantageous as it will avoid problems of infinite EDP response.

Finally, testing efficiency as well as sufficiency for local IDR and PFA values, rather than just the maximum interstory drift, is essential for IMs that are geared towards loss assessment. This idea was first tested in a rudimentary form in NIST [34] and is put forward herein as a rigorous test for selecting IMs for vulnerability assessment. Thus, for each $N$-story building ( $N=7,12,20$ for highrise or 1, 2, 4 for lowrise), the candidate IMs will be checked for $2 \mathrm{~N}+3$ different EDPs: One IDR per story ( $\mathrm{N}$ total), one PFA per floor $(\mathrm{N}+1$ total to include the ground level) plus the overall maximum interstory drift and the roof drift. The latter two may not be used per se in the vulnerability calculations, yet they often appear in fragility estimates used in simpler methodologies and, thus, should not be discounted.

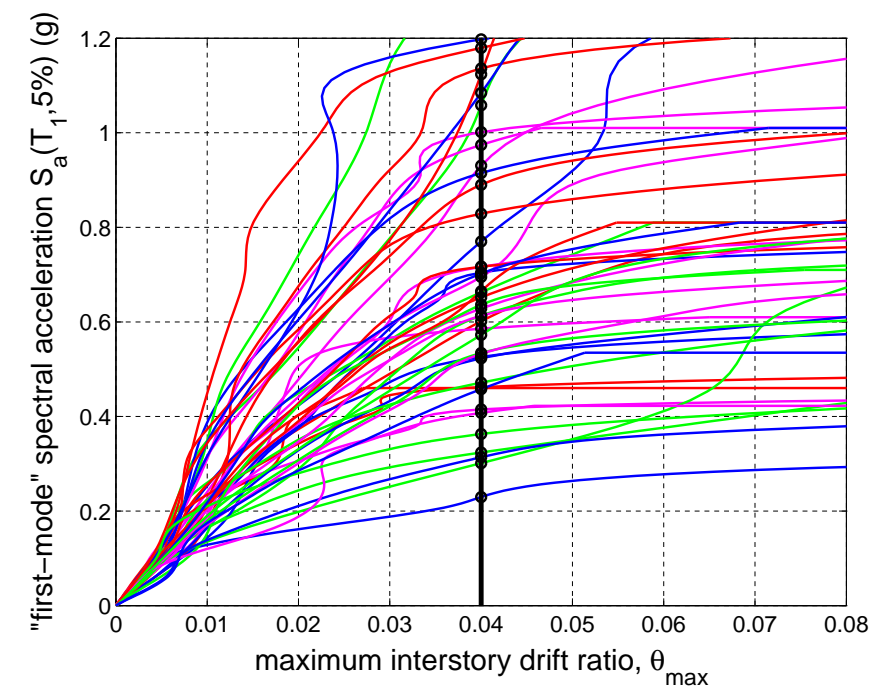

Figure 3. 44 IDA curves (each color line corresponding to a different ground motion) for the No0 12-story index buildings and a "vertical stripe" of IM "capacity values" at an interstory drift level of $4 \%$.

\subsection{IM efficiency testing}

Figures 4 and 5 illustrate for the No0 12-story and the 3ELF 4-story index buildings and the eight considered IMs, the "maximum over height" dispersion $\beta_{\mathrm{IM}}$ (i.e. standard deviation of the natural logarithm) of the IM capacities given IDR or PFA. The range of both EDP types has been selected to span from the elastic up to the inelastic level of structural response. The maximum $\beta_{\mathrm{IM}}$ signifies the worst performance of a candidate IM along the height of the building. The "average $\beta_{\mathrm{IM}}$ over height" of the building is also plotted to indicate the average efficiency of each IM at each level of deformation. Although showing the results from a single index structure per building class, the same trends persist in each of the seven highrise or the six lowrise index buildings, therefore the discussion to follow should be considered to be applicable to each and every one that belongs to the same class. 
Considering the overall results, some characteristic features appear. The maxima of dispersion given IDR for the highrise index building (Figure 4a), show some surprising high values in the early elastic region. This is a by-product of the higher mode effects in these tall buildings, where a single story is heavily influenced by the ground motion variability associated with modes other than the first (and maybe the second) that are not captured by any of the considered IMs. Note that simply including such modes in $S_{a g m}\left(T_{\mathrm{i}}\right)$ is not the same as accurately predicting their effects at a given story using appropriate participation factors as done at the roof level by Luco and Cornell [5]. This causes a characteristic early increase in dispersion that quickly disappears as the first traces of inelasticity appear in the structure, a trend which is not observed in the lowrise buildings where the effect of higher modes, if any, in the early elastic region is small (see Figure 5a). As the average dispersion plots of IDR given IM in Figure 4b show, the aforementioned crest is indeed an isolated local effect, rather than a feature over the entire structure. A somewhat similar hump appears for PFAs, only now shifted away from elasticity and close to the (nominal/global) yield region of the structure and it is common both in lowrise and highrise index buildings (see Figures $4 \mathrm{c}$ and $5 \mathrm{c}$ ). It seems that regardless of the IM, there is significant difficulty in capturing the complex interaction of modes that happens in the yield and post-yield region as well as the gradual transition to an elongated first-mode period that is characteristic of large deformations (e.g, see [42]). This is generating dispersions that can grow from $40 \%$ up to $80 \%$ for the highrise frames and from $30 \%$ up to $70 \%$ for the lowrise ones. Furthermore, this is not a localized effect, but rather widespread throughout the height of the structure, as it appears both in the maximum (Figure $4 c$ and $5 c$ ) and average dispersions (Figure $4 d$ and 5d).

Moreover, while IM ranking would be clear across all IDR values for the highrise building in Figures $4 \mathrm{a}$ and $4 \mathrm{~b}$, this is not the case for PFAs (Figures $4 \mathrm{c}$ and $4 \mathrm{~d}$ ). Some of the best performing IMs at the "yield-hump" lose their efficiency for higher PFAs and vice-versa. Apparently, this has to do with the sensitivity of PFAs to higher modes. Thus, IMs that are heavily weighted in favor of higher modes, such as $S_{a g m}\left(T_{\mathrm{i}}, 5 \%\right)_{2}$ with 7 equally weighted periods, six of which are below the first mode period $T_{1}$, do well close to yield ,where such higher modes still matter. Later on, when the structure has almost settled into a plastic mechanism and behaves closer to an SDOF with an elongated first-mode period, the IMs that put more weight in periods higher than $T_{1}$ are favored, e.g. $S_{a g m}\left(T_{\mathrm{i}}, 5 \%\right)_{5}$ having 5 equally weighed periods of which three are at or above $T_{1}$. In general, when the structure leaves the complex phase that occurs when elements start to yield, and adopts a certain plastic mechanism, much of the uncertainty disappears and the performance of each IM stabilizes greatly, both in PFA and IDR. The most useful conclusion, though, is that there does not seem to be a perfect single IM that is optimal for all EDPs. When considering both accelerations and drifts across different ranges of structural behavior, we have to accept a compromise.

The IM ranking for the lowrise buildings is less clear across the entire range of IDR values (Figures $5 \mathrm{a}$ and $5 \mathrm{~b}$ ), with $S_{a}\left(T_{1 \mathrm{~m}}\right)$ showing the best performance in the elastic region and $S_{\text {agm }}\left(T_{\mathrm{i}}, 5 \%\right)_{5}$ taking advantage in regions where the spread of inelasticity results in substantially elongated periods. Quite notably, the dispersion associated with the $S_{a g m}\left(T_{\mathrm{i}}, 5 \%\right)_{5}$ is in the order of $30 \%$ for both building classes (compare Figures $4 \mathrm{~d}$ and $5 \mathrm{~d}$ ). The dispersion is only marginally higher for the higher-mode influenced tall structures, indicating a stable performance regardless of structural characteristics. Regarding the IM ranking for the lowrise PFAs, the performance of each IM also eventually stabilizes but at considerably higher PFAs compared to the highrise case. In generally, one should expect shorter and stiffer structures to attract higher spectral accelerations and associated PFAs before yielding, resulting to this characteristic right-shift in the morphology of the diagrams. 


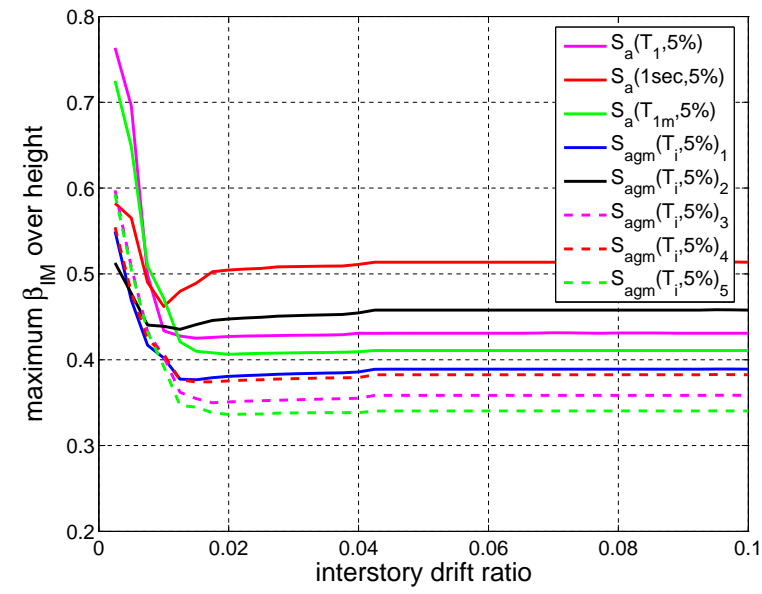

(a) maximum dispersion of IDR given IM (No0)

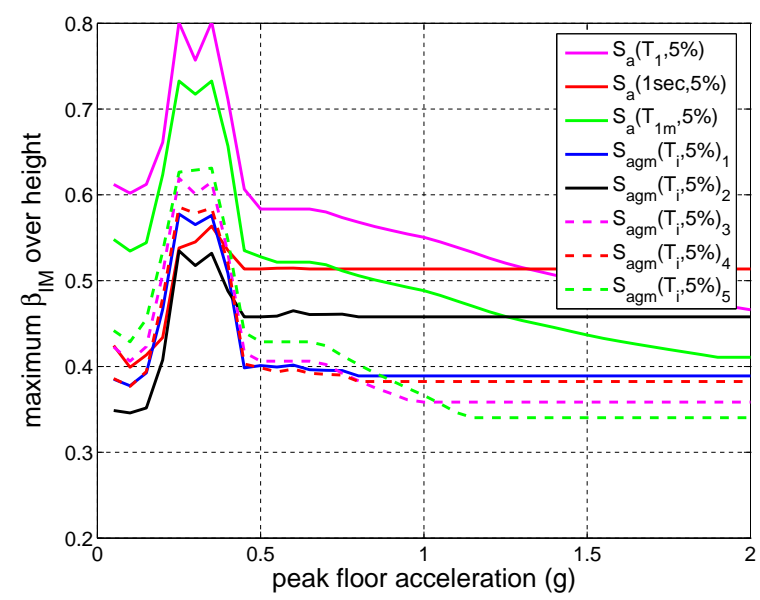

(c) maximum dispersion of PFA given IM (No0)

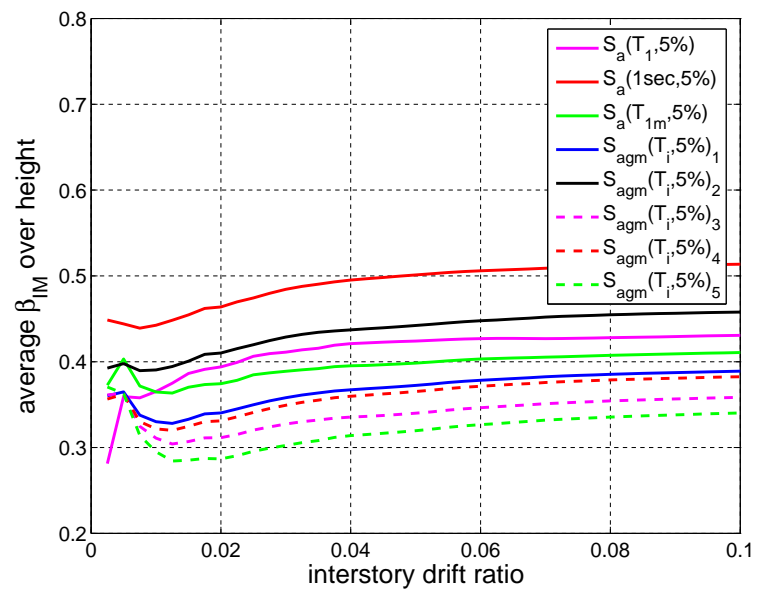

(b) average dispersion of IDR given IM (No0)

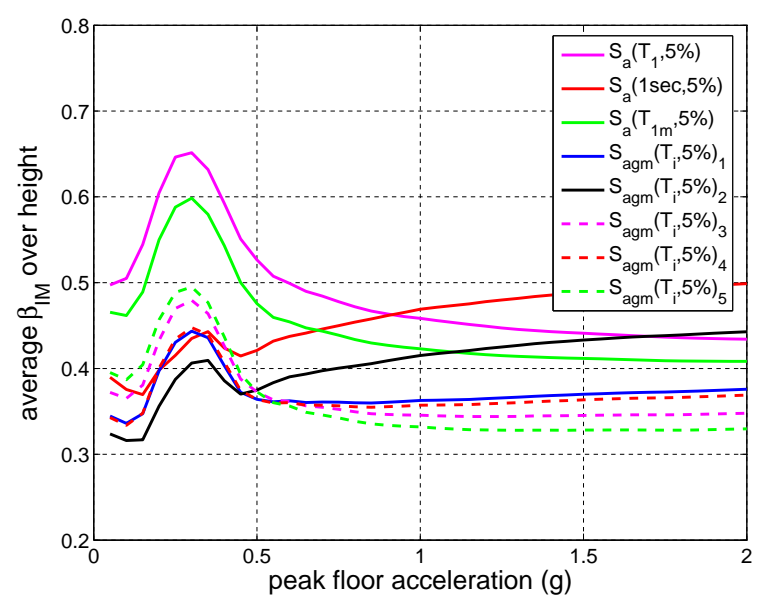

(d) average dispersion of PFA given IM (No0)

Figure 4. Maximum and average dispersions of the IM for given values of the IDR and PFA response of the No0 12-story index building considering eight IMs.

Evidently, among the least efficient IMs across the examined EDP range, is $S_{a}(1 \mathrm{sec}, 5 \%)$, especially when considering IDR as a response measure. Its performance is particularly worse for the highrise case compared to most other IMs, an interesting fact given that it is often a popular choice for highrise vulnerability studies. The dispersions achieved by $S_{a}\left(T_{1}\right)$, which is useful for single buildings, and $S_{a}\left(T_{1 \mathrm{~m}}\right)$ were also proven to be high, rendering their use relatively expensive: More ground motion records will need to be employed for a good estimate of the distribution of loss. Among the remaining IMs and considering their performance both in elastic and inelastic regions for IDR and PFA, the $S_{a g m}\left(T_{\mathrm{i}}\right)_{4}$, was proven to provide relatively stable dispersion estimates. It employs four periods, the $T_{1 \mathrm{~m}}$ and the $T_{2 \mathrm{~m}}$ and their "elongated" versions by a factor of $50 \%$, thus equally favoring the first and second mode. $S_{a g m}\left(T_{\mathrm{i}}\right)_{5}$, having one more longer-than- $T_{1}$ period is an equally good choice, showing better efficiency practically everywhere with the exception of the PFA hump where it performs slightly worse than other IMs. In conclusion, it seems that a successful IM can be created by specifying an appropriate period range that includes periods both above and below $T_{1 \mathrm{~m}}$ and uses the geometric mean of the spectral accelerations evaluated at these periods (see also $[21,22])$. 


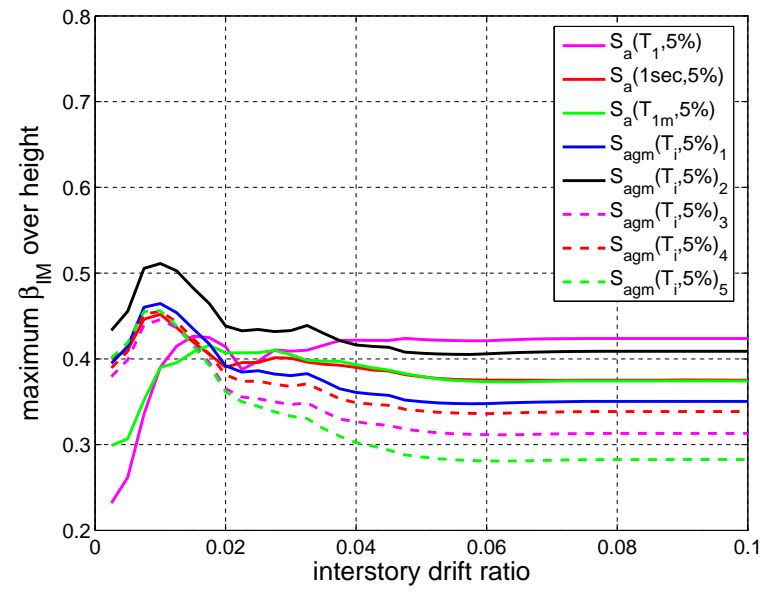

(a) maximum dispersion of IDR given IM (3ELF)

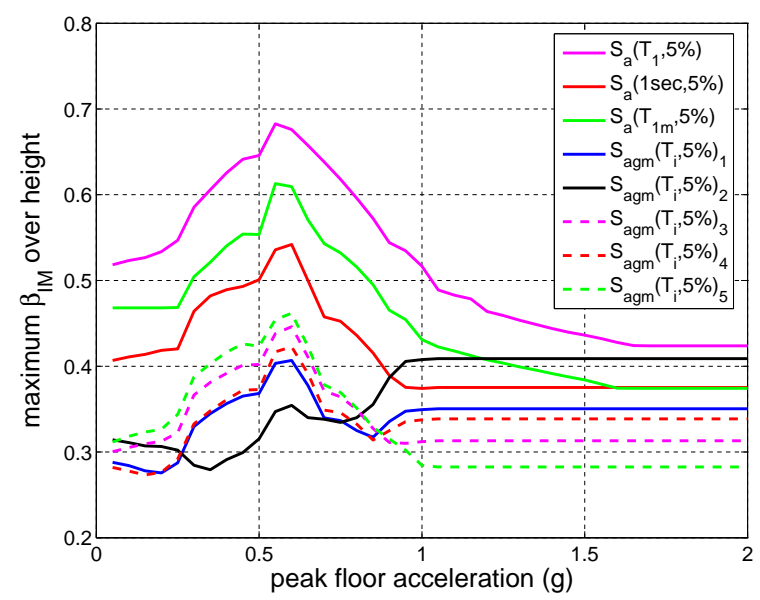

(c) maximum dispersion of PFA given IM (3ELF)

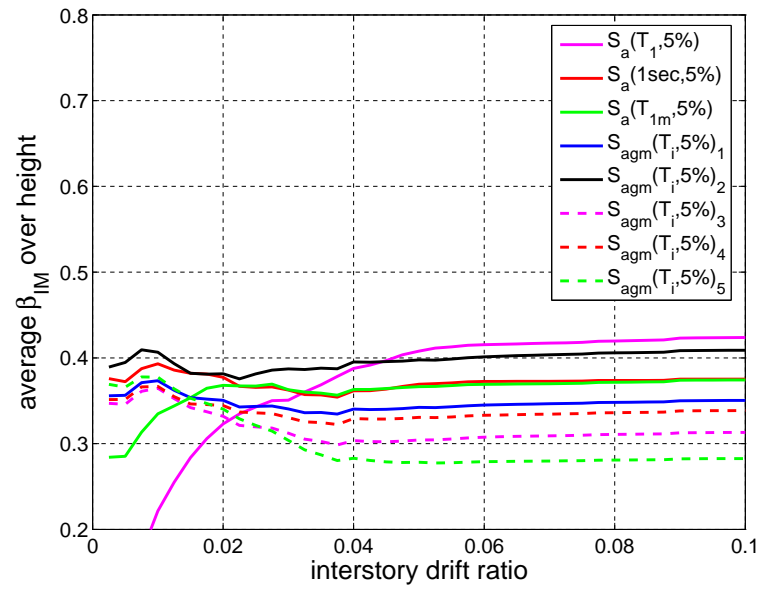

(b) average dispersion of IDR given IM (3ELF)

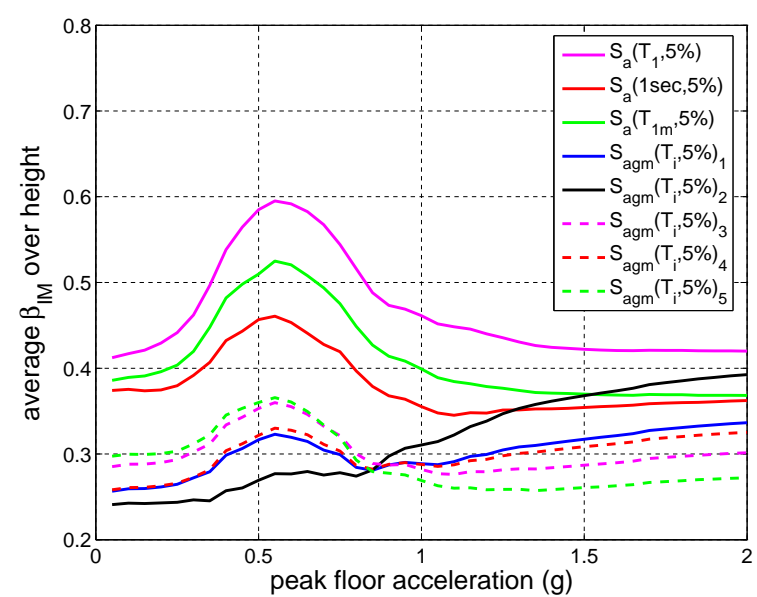

(d) average dispersion of PFA given IM (3ELF)

Figure 5. Maximum and average dispersions of the IM for given values of the IDR and PFA response of the 3ELF 4-story index building considering eight IMs.

\subsection{IM sufficiency testing}

The sufficiency of the considered IMs is tested against the moment magnitude $M_{w}$ and the epsilon $\varepsilon\left(T_{1}\right)$ ground motion characteristics. To accomplish this, a linear regression analysis between $\ln (\mathrm{IM} \mid \mathrm{EDP})$, i.e. the logarithm of IM capacity values for a given value of any of the EDPs, and the $M_{w}$ or the $\varepsilon\left(T_{1}\right)$ value of the record was undertaken as follows,

$$
\ln (I M \mid E D P)=a+b M_{w}
$$

or

$$
\ln (I M \mid E D P)=a+b \varepsilon\left(T_{1}\right) .
$$

The logarithm of IM|EDP was adopted, since the latter is generally lognormally distributed for the considered range of IMs and EDPs [34]. As already mentioned, the proposed methodology for checking sufficiency is advantageous, since it avoids the problems associated with performing the regression analysis over the entire EDP range, an approach that obviously becomes problematic close to collapse (defined here as dynamic instability), but has been found considerable use in previous studies (e.g.[7, 39]). On the other hand, the proposed process reduces the number of data points available for fitting Eqs 2-3 since the fitting process takes place at distinct EDP levels, thus requiring a large number of records for sound interpretation. In general, useful results may be obtained by checking the sufficiency of 
the IMs against $M_{w}$ or $\varepsilon\left(T_{1}\right)$ across the structural response range by means of standardized statistical significance testing. Given the large number of EDPs to be tested, the results of such tests will be summarized by the following quantities:

(a) The ratio of the number of EDPs for which $M_{w}$ or $\varepsilon\left(T_{1}\right)$ is significant over the total number of EDPs considered,

(b) The average $p$-value for significance of the $M_{w}$ or $\varepsilon\left(T_{1}\right)$ regression,

(c) The average dispersion $\beta$ explained by $M_{w}$ or $\varepsilon\left(T_{1}\right)$,

(d) The maximum dispersion $\beta$ explained by $M_{w}$ or $\varepsilon\left(T_{1}\right)$,

(e) The average $M_{w}$ or $\varepsilon\left(T_{1}\right)$ regression coefficient,

(f) The maximum $M_{w}$ or $\varepsilon\left(T_{1}\right)$ regression coefficient.

It should be noted here that the above variables only provide statistical evidence in favor or against sufficiency, rather than conclusive proof. This is especially true for the evaluation of "statistical significance" via the $p$-value. The $p$-value quantifies the statistical significance of the regression coefficient $b$ on $M_{w}$ or $\varepsilon\left(T_{1}\right)$ (Eqs 2,3). It is defined as the probability of rejecting the null hypothesis that the slope coefficient $b$ is zero. Hence, a small $p$-value (typically $p<0.05$ ) indicates that the null hypothesis (i.e. $b$ equals zero) may be rejected; consequently, the coefficient $b$ (Eqs 2,3) is statistically significant and the tested IM is insufficient. While this information (items a,b above) may be an indication of $M_{w}$ or $\varepsilon\left(T_{1}\right)$ having some influence on the results, it says little about the actual magnitude of this influence, which may well be of no practical significance [43]. This is the reason for plotting the dispersion explained by each new parameter (items c,d), and the actual value of the regression coefficient (items e,f) that can help us understand the magnitude of the influence brought on by $M_{w}$ or $\varepsilon\left(T_{1}\right)$. Thus, a low $p$-value may not mean much if the associated parameter $\left(M_{w}\right.$ or epsilon) cannot effect much of a change. Similarly, a high $p$-value does not necessarily imply sufficiency. It simply says that there is too much noise in the data to let us see whether there is any significant influence. In other words, a good IM that reduces the dependence on $M_{w}$ or $\varepsilon\left(T_{1}\right)$ may be tied to low $p$-values if it also drastically reduces the variability in the data, thus making it easier for us to detect any extraneous influence. Likewise, an overall bad IM that introduces higher dependence on seismological parameters will typically also be inefficient, thus producing IM-capacity values with large dispersions that can hide this influence in the data noise. In other words, considerable care is required when interpreting such results.

To showcase the IM selection methodology for a building class, we will report for brevity the statistical testing results for a single building, which is part of the highrise class (i.e. No0 12-story in Table 1). The sufficiency testing for highrise and lowrise buildings yields similar, although not identical, results and trends. The latter is also the case between the index buildings of the same class. Nevertheless, highrise buildings are considered to impose more severe challenges to the IM selection problem than those induced by the lowrise buildings, mainly due to the nontrivial contribution of the higher modes. Hence, any findings regarding the IM's sufficiency obtained on a highrise class base are generally applicable to the lowrise case.

Figures 6 and 7 illustrate the sufficiency testing results for the No0 12-story index building against $M_{w}$ and $\varepsilon\left(T_{1}\right)$, respectively, for all story IDRs, the overall maximum interstory and the roof drift. Clearly, across the examined IDR response range, there is significant scatter, but a common trend is that the majority of the examined IMs are becoming insufficient against $M_{w}$ as the structure approaches its collapse state (e.g. see Figure 6a). Exactly the opposite trend is observed while checking the sufficiency of the IMs against $\varepsilon\left(T_{1}\right)$ (see Figure 7a). In that case, there is a large number of IDR-based EDPs where $\varepsilon\left(T_{1}\right)$ is 
significant right before yielding (with the exception of $S_{a}\left(T_{1 \mathrm{~m}}\right)$ and the $S_{a}\left(T_{1}\right)$ ) and it becomes insignificant at more severe damage levels, rendering the examined IMs sufficient for these levels. For PFAs over the height of the buildings, Figure 8 shows that several IMs are insufficient against $M_{w}$ for acceleration values higher than $0.5 \mathrm{~g}$ at any floor. The notable exception here is $S_{a}(1 \mathrm{sec})$ and $S_{a g m}\left(T_{i}\right)_{5}$, the two having practically no dependence on magnitude at all. Sufficiency results for $\varepsilon\left(T_{1}\right)$ in Figure 9 show different trends compared to $M_{w}$. Now, insufficiency appears for most IMs at the PFA hump (values lower than $0.5 \mathrm{~g}$ ) and then rapidly declines. The outcome seems to favor $S_{a}(1 \mathrm{sec})$, whereas $S_{a}\left(\mathrm{~T}_{1}\right), S_{a}\left(\mathrm{~T}_{1 m}\right)$ perform quite badly and $S_{a g m}\left(T_{i}\right)_{5}$ is about average.

The aforementioned findings are further supported by Figures $6 \mathrm{~b}$ and $7 \mathrm{~b}$, that illustrate the average $p$-value for $M_{w}$ and $\varepsilon\left(T_{1}\right)$, respectively. For the case at hand, by inspecting Figure $6 \mathrm{~b}$ we can say that the examined IMs are insufficient against $M_{w}$ with the majority of them showing quite a significant dependence of IM on $M_{w}$ (demonstrated by small $\mathrm{p}$ values, $\mathrm{p}<0.05)$. By contrast, most of the IMs are found to be sufficient against the $\varepsilon\left(T_{1}\right)$ with the reported $p$-values being in the range of $\sim 0.6-1$. The dispersion $\beta$ explained by $M_{w}$ (Figures $6 \mathrm{c}-$ d) or by $\varepsilon\left(T_{1}\right)$ (Figures $7 \mathrm{c}-\mathrm{d}$ ) was found to be very low for almost all cases. This finding shows that in general adding $M_{w}$ or $\varepsilon\left(T_{1}\right)$ in the definition of the tested IMs cannot offer much in terms of reducing their dispersion, i.e. improving their efficiency. It also means that there is only a little part of the value of each IM-capacity point that can be explained by the two seismological parameters. Conversely, we cannot expect the magnitude of any influence wielded by $M_{w}$ or epsilon to be large. This is verified by Figures $6 \mathrm{e}-\mathrm{f}$ and $7 \mathrm{e}-\mathrm{f}$ where the coefficient $b$ of the regression is shown to be quite low for the best performing IMs, mostly showing average absolute values less than 0.05 . Considering that for the given set of records epsilon roughly ranges from -1.6 to +1.2 (mean of $\sim 0.0$ ) at $T_{1 m}$, the value of $b=0.05$ indicates a maximum change due to epsilon vis-à-vis the median IM value by a factor of $\exp (b \cdot 1.6)=1.08$. For our $M_{w}$ values ranging from 6.5 to 7.6 (mean of $\sim 7.0$ ), the same factor is of the order of $\exp (b \cdot 0.6)=1.03$; it can be considered to be 1.0 for all practical purposes. Thus, any expected bias is going to have extremely low impact. Perhaps the only exception appears for the story drift at one or two stories at mid-height (Figure 6f), that cause, even for one of the best performing IM such as $S_{a g m}\left(T_{\mathrm{i}}\right)_{5}$, a value of $b=0.25$ at a drift of $4 \%$. Here, $M_{w}$ will become locally more important, probably due to driving the higher modes. Then we may expect that the maximum change with respect to the median IM value will be by a factor of $\exp (b \cdot 0.6)=1.16$. Still, this appears only locally and for a specific range of response, therefore we can safely assume that it will not bias the overall building vulnerability assessment. Similar observations can be made for PFA through Figures 8-9, where only some localized insufficiency at accelerations in the order of $0.5 \mathrm{~g}$ seems to mar the performance of the best IMs, e.g, $S_{a g m}\left(T_{\mathrm{i}}\right)_{5}$; still this is also not associated with any excessive values of the regression coefficient. 


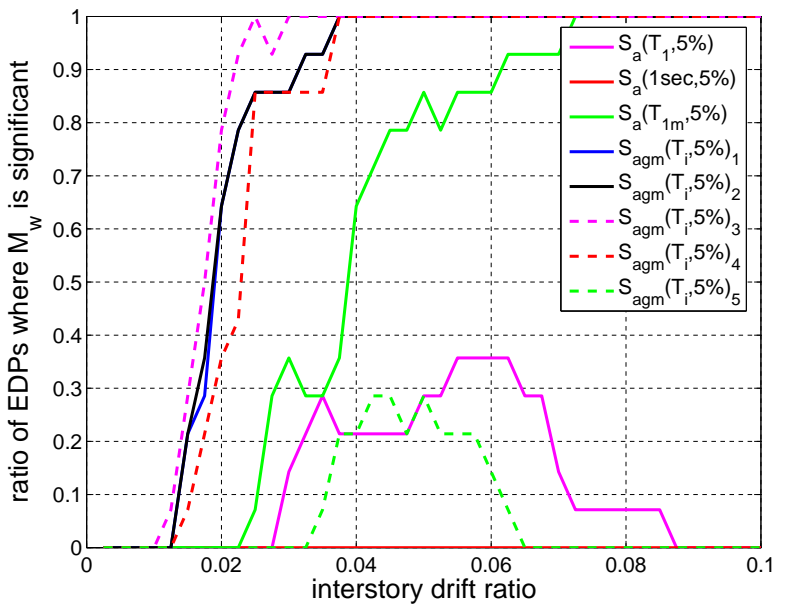

(a) ratio of IDR for which $M_{w}$ is significant

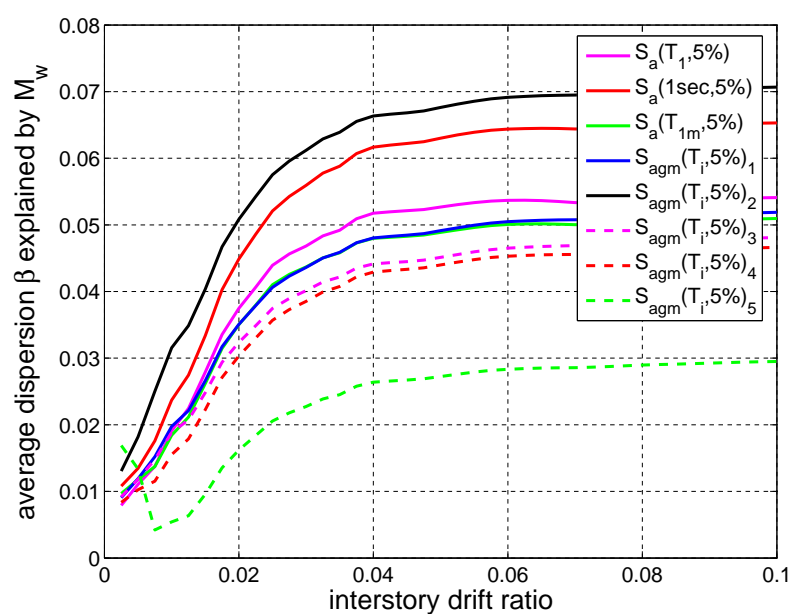

(c) average dispersion $\beta$ explained by $M_{w}$

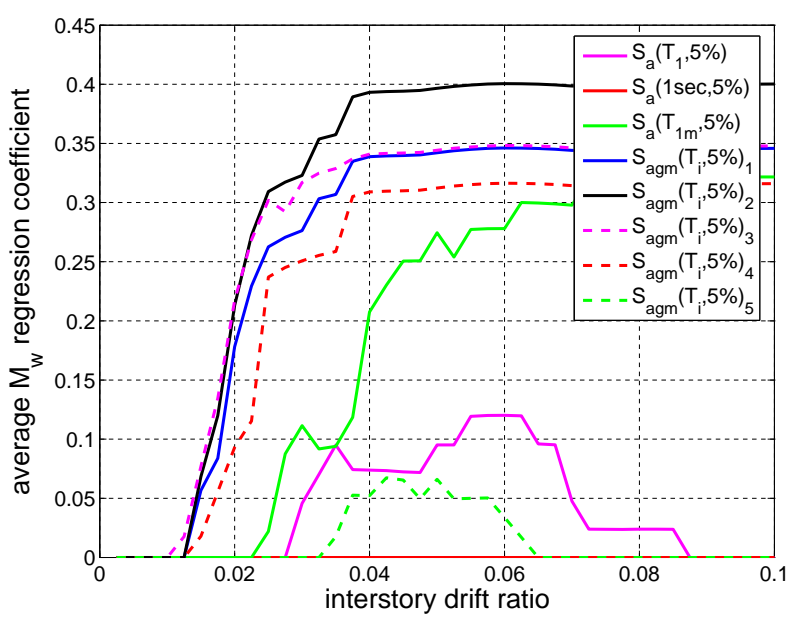

(e) average $M_{w}$ regression coefficient

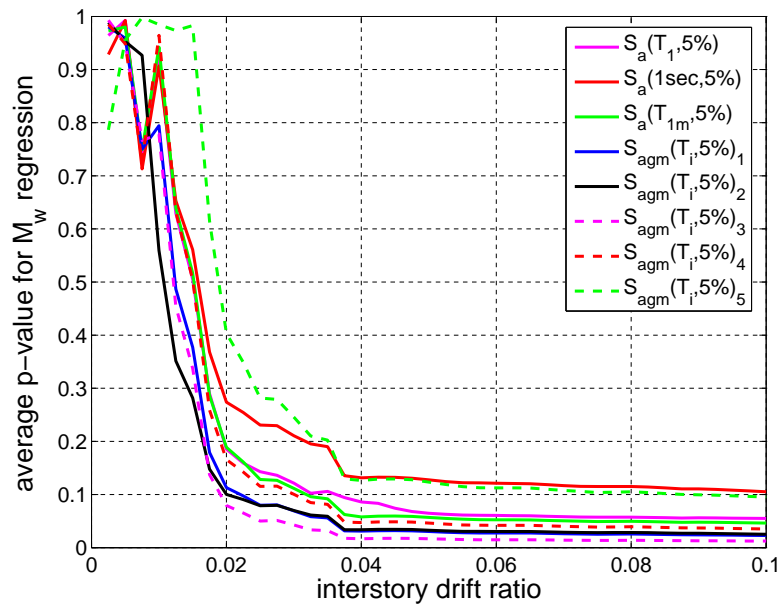

(b) average $p$-value for $M_{w}$ regression

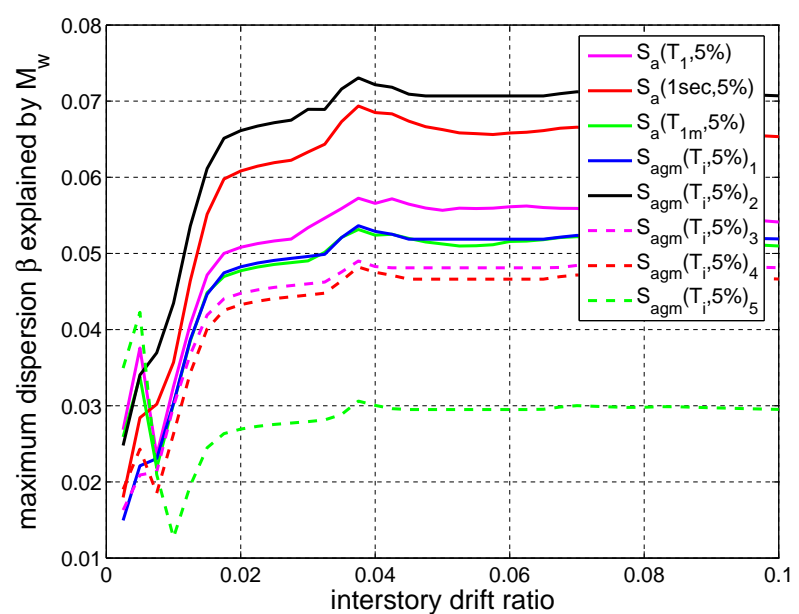

(d) maximum dispersion $\beta$ explained by $M_{w}$

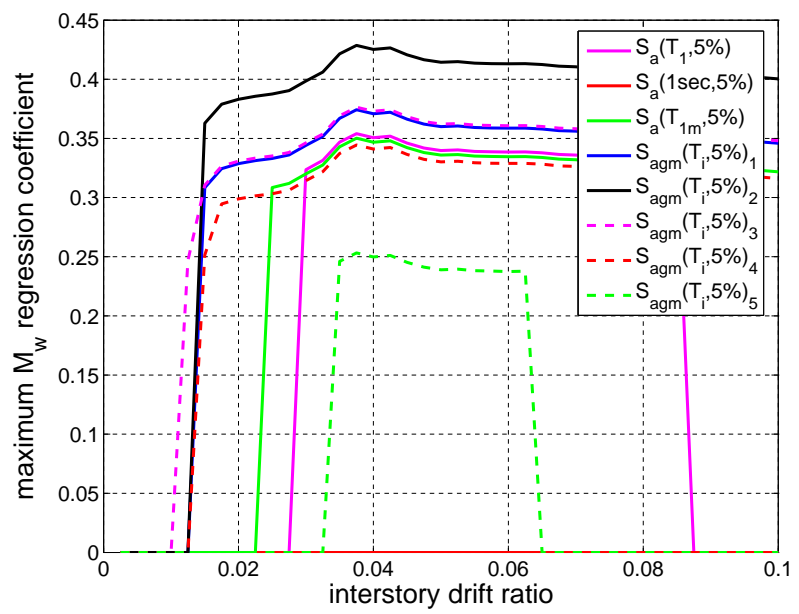

(f) maximum $M_{w}$ regression coefficient

Figure 6. Variables for testing the sufficiency of the IMs against $M_{w}$ across the IDR range (No0 12-story index building). 


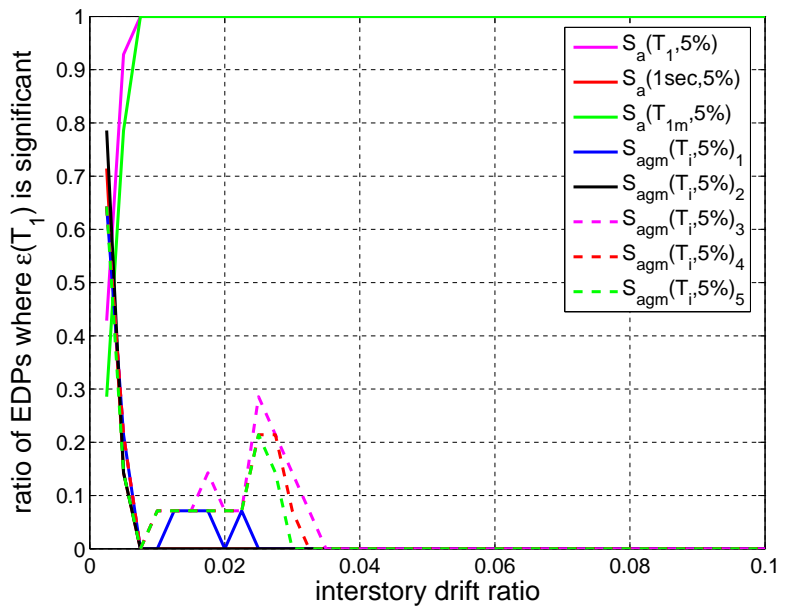

(a) ratio of IDR for which $\varepsilon\left(T_{1}\right)$ is significant

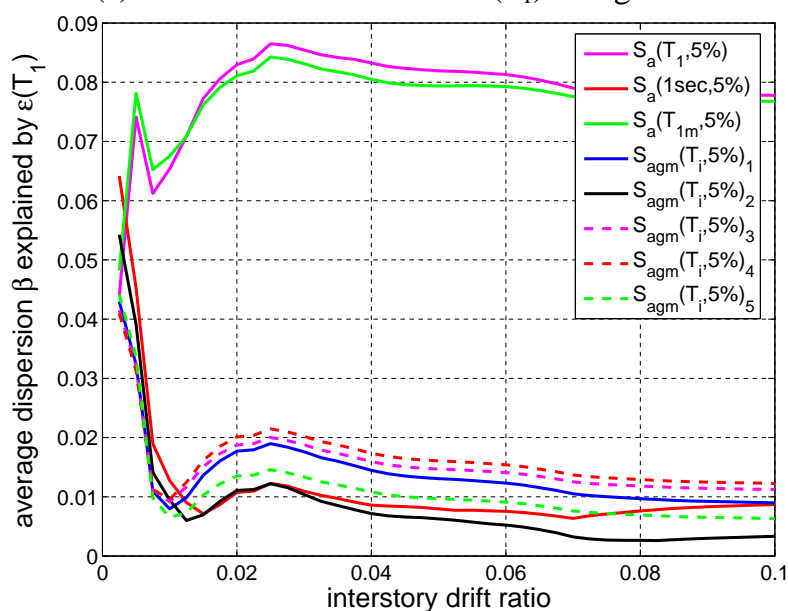

(c) average dispersion $\beta$ explained by $\varepsilon\left(T_{1}\right)$

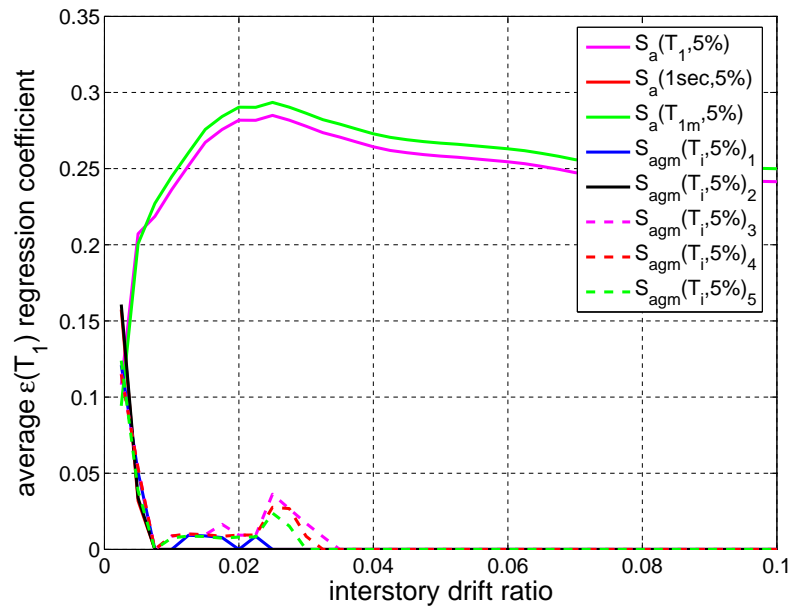

(e) average $\varepsilon\left(T_{1}\right)$ regression coefficient

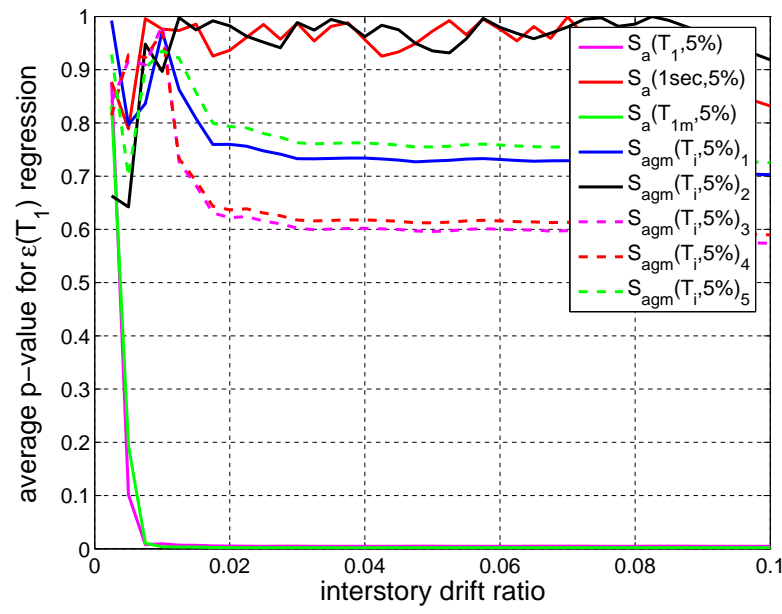

(b) average $p$-value for $\varepsilon\left(T_{1}\right)$ regression

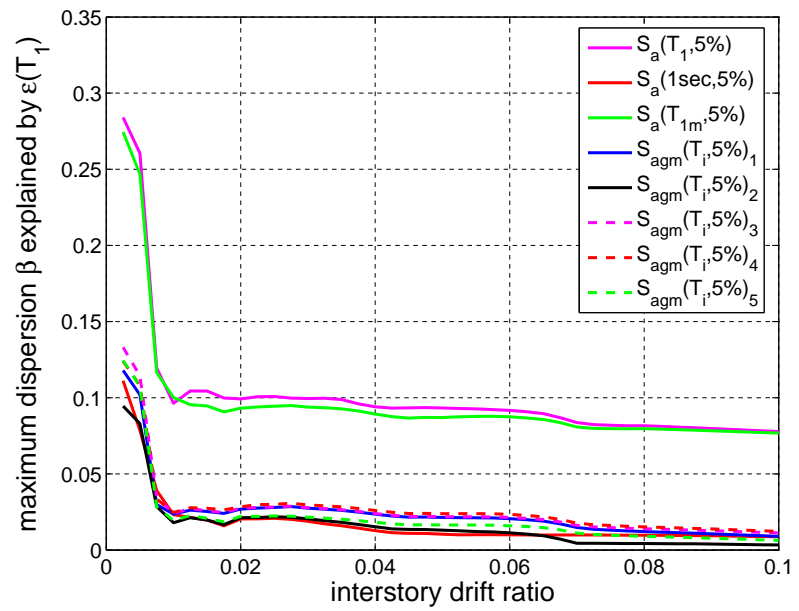

(d) maximum dispersion $\beta$ explained by $\varepsilon\left(T_{1}\right)$

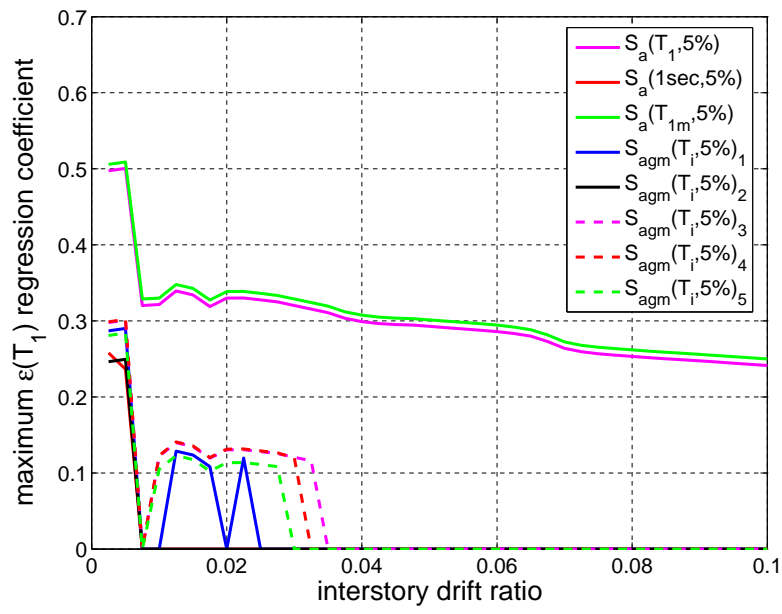

(f) maximum $\varepsilon\left(T_{1}\right)$ regression coefficient

Figure 7. Variables for testing the sufficiency of the IMs against $\varepsilon\left(T_{1}\right)$ across the IDR range (No0 12-story index building). 


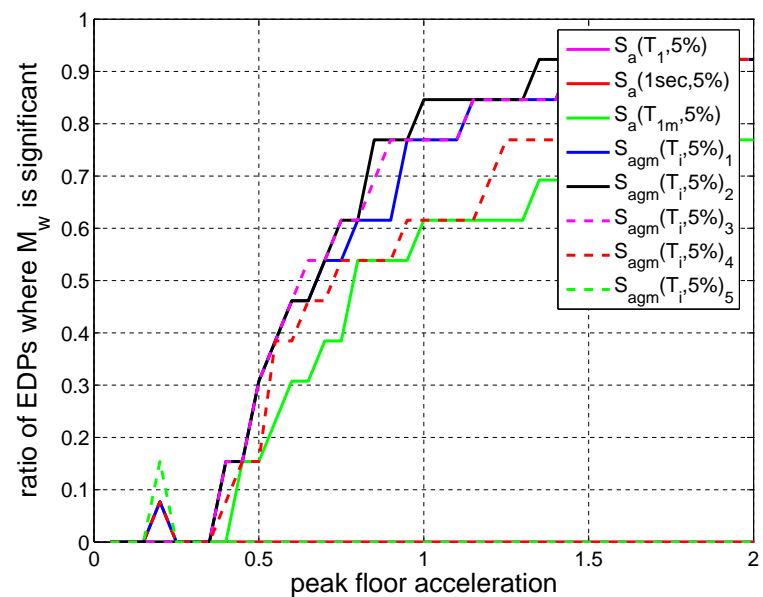

(a) ratio of PFA for which $M_{w}$ is significant

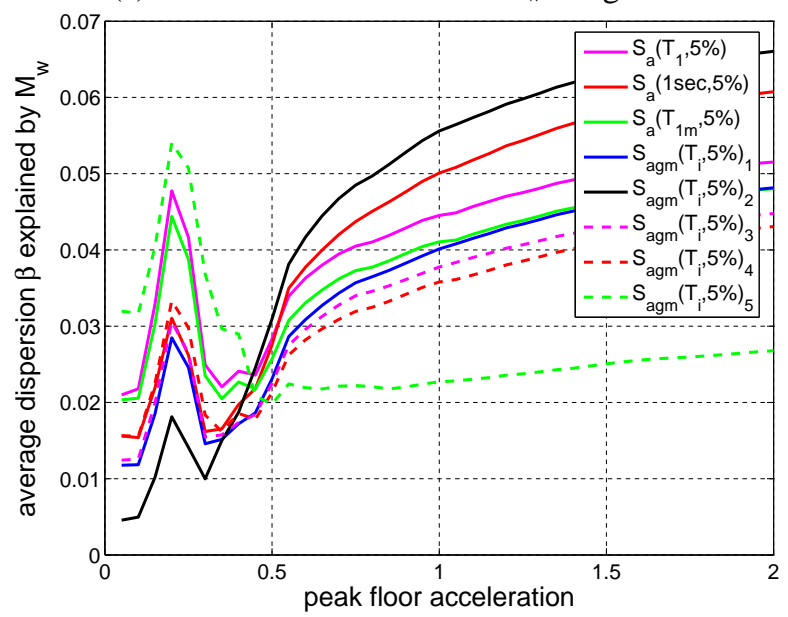

(c) average dispersion $\beta$ explained by $M_{w}$

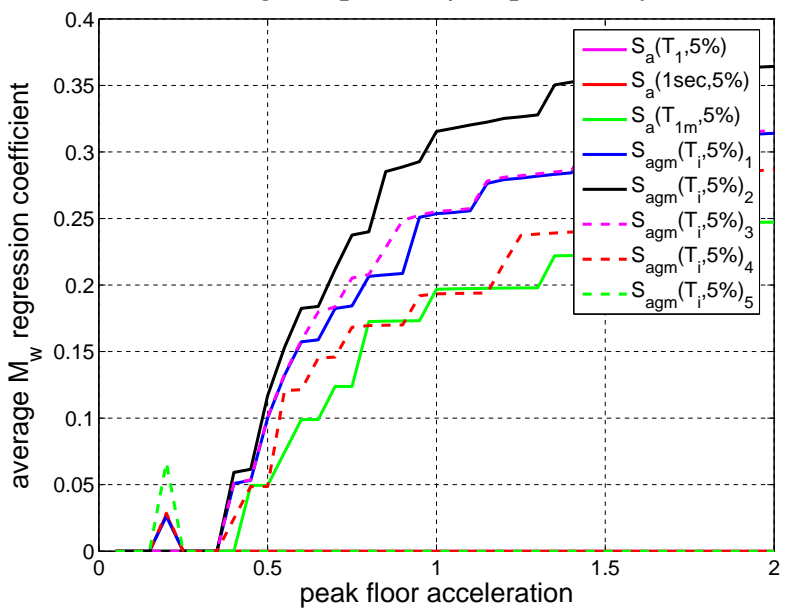

(e) average $M_{w}$ regression coefficient

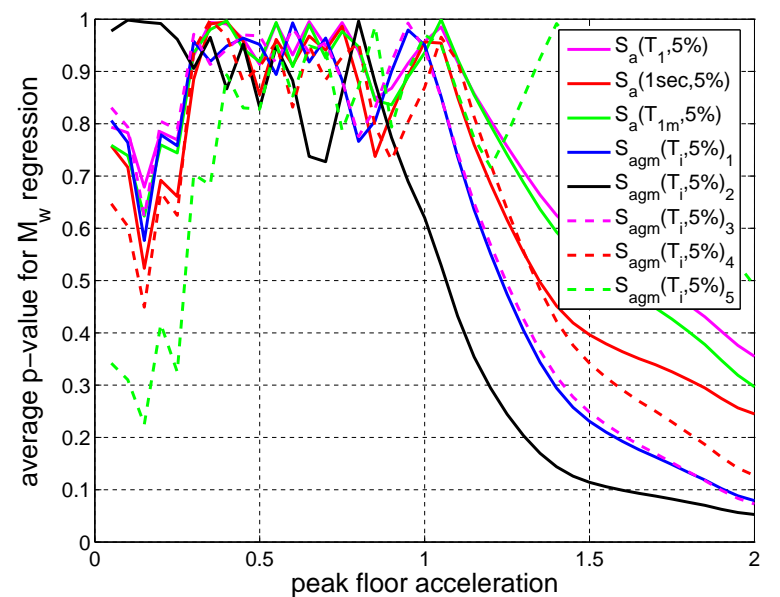

(b) average $p$-value for $M_{w}$ regression

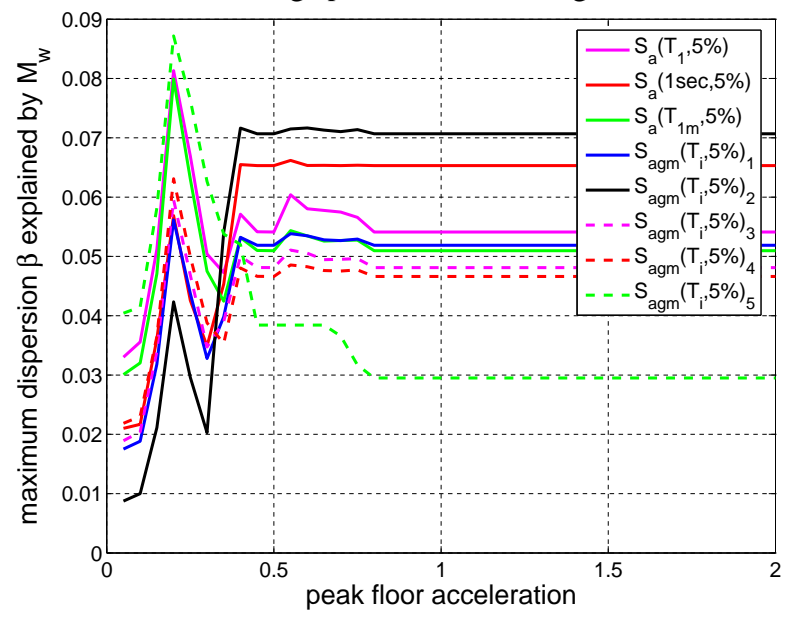

(d) maximum dispersion $\beta$ explained by $M_{w}$

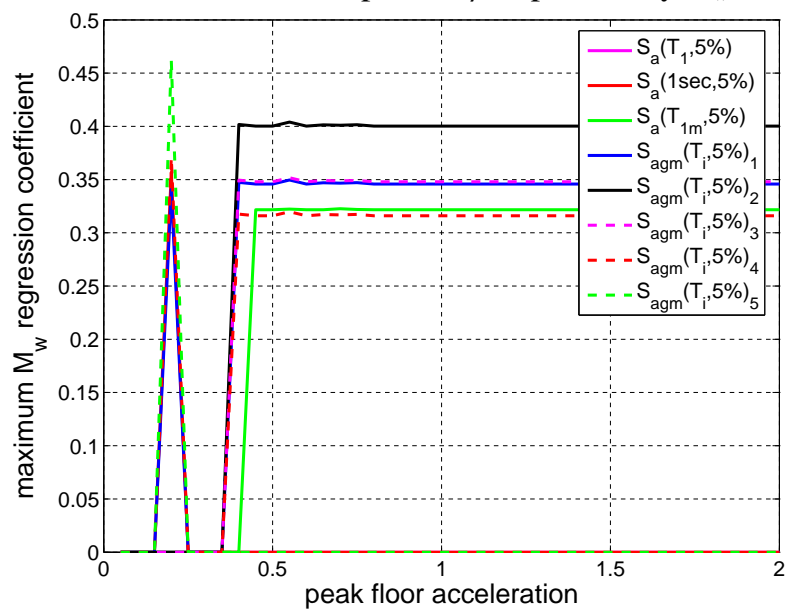

(f) maximum $M_{w}$ regression coefficient

Figure 8. Variables for testing the sufficiency of the IMs against $M_{w}$ across the PFA range (No0 12-story index building). 


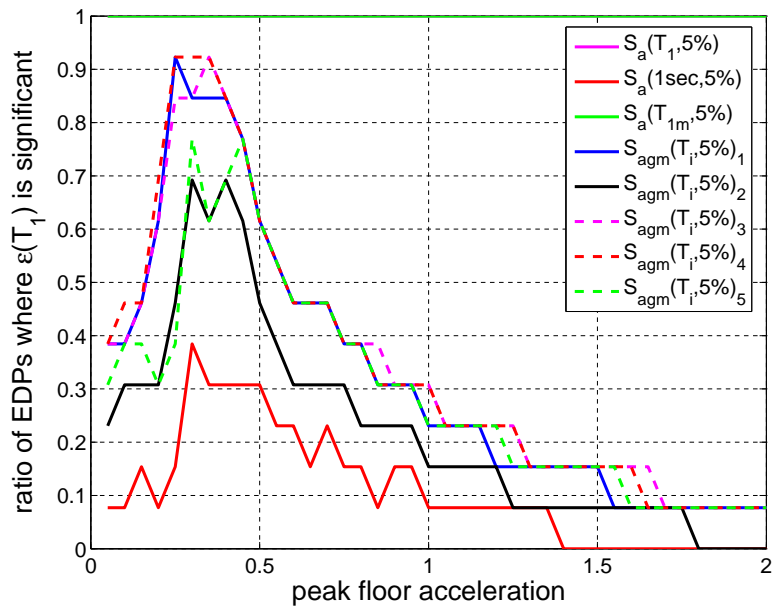

(a) ratio of PFA for which $\varepsilon\left(T_{1}\right)$ is significant

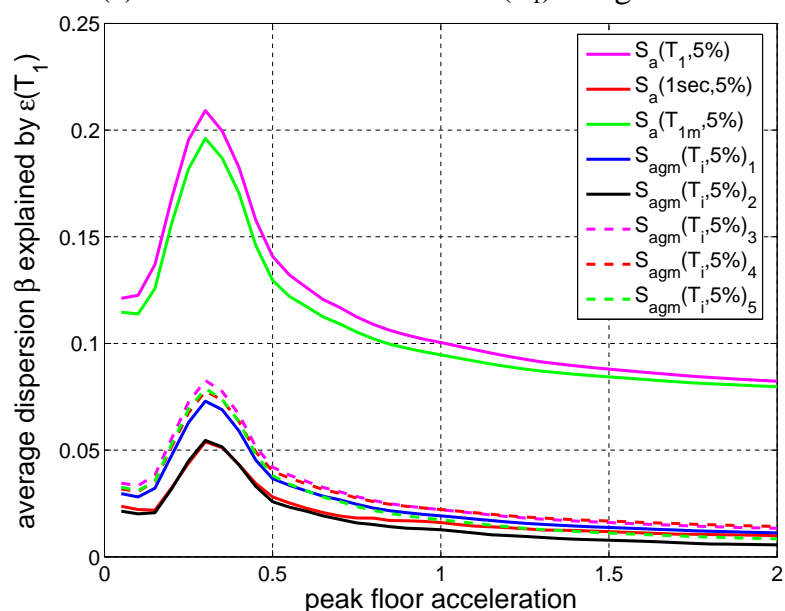

(c) average dispersion $\beta$ explained by $\varepsilon\left(T_{1}\right)$

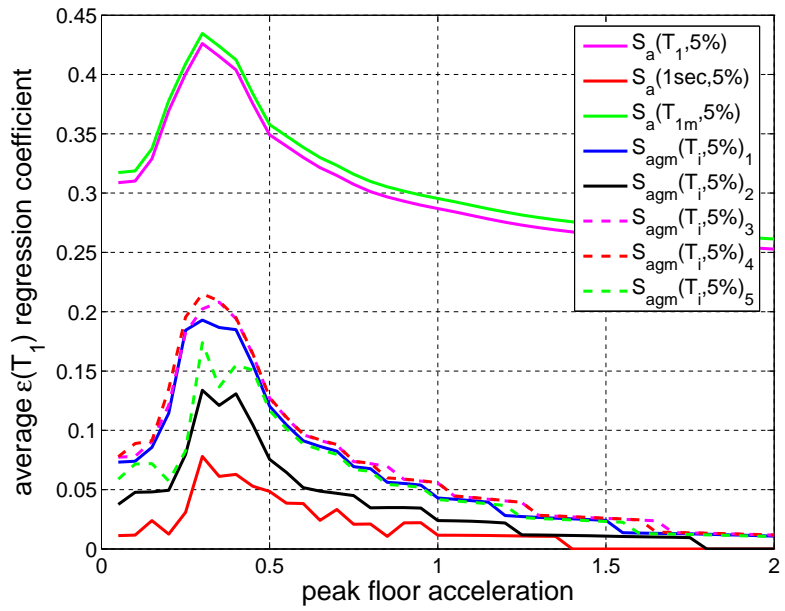

(e) average $\varepsilon\left(T_{1}\right)$ regression coefficient

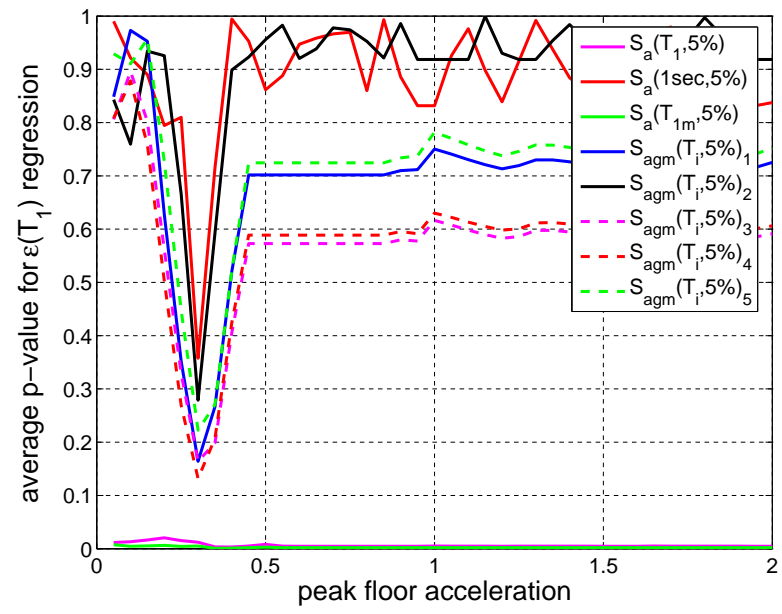

(b) average $p$-value for $\varepsilon\left(T_{1}\right)$ regression

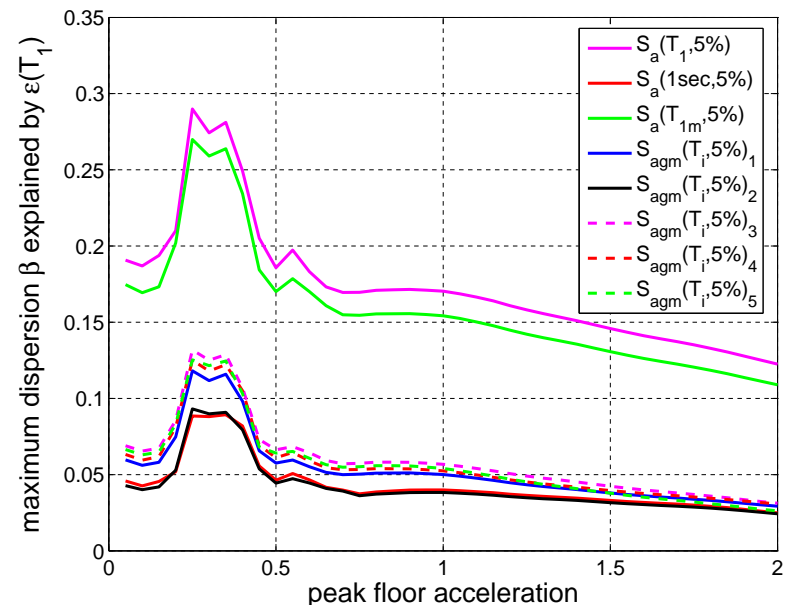

(d) maximum dispersion $\beta$ explained by $\varepsilon\left(T_{1}\right)$

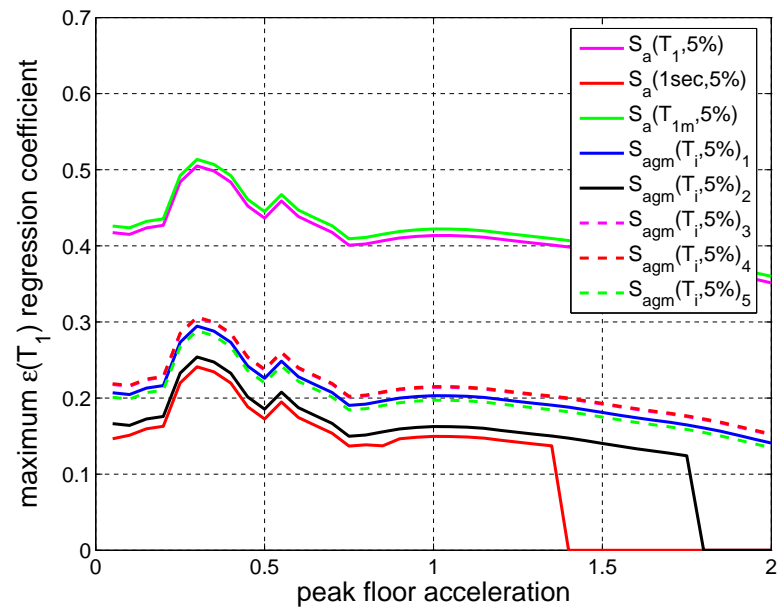

(f) maximum $\varepsilon\left(T_{1}\right)$ regression coefficient

Figure 9. Variables for testing the sufficiency of the IMs against $\varepsilon\left(T_{1}\right)$ across the PFA range (No0 12-story index building).

It might be interesting to speculate on what would be the value of such factors for ground motion records having magnitudes or epsilon values that are outside the bounds of our current sample. Although this would amount to extrapolation, the aforementioned analysis and the results of Luco and Bazzurro [18] at least suggest that such records would probably wield higher influence. This means, for example, that it would not be advisable to employ records 
with $M_{w}=5.0$ when analyzing these modern, well-designed structures. The records should be at least strong enough to drive the structures into the nonlinear range without much scaling. Within such reasonable constraints, our results suggest that $p$-values less than the $5 \%$ limit do not necessarily mean significant sensitivity of the estimated vulnerability (or losses) to either magnitude or epsilon, as long as a well-performing IM is selected. In other words, even disregarding the fact that a careful record selection is not possible without having a specific site in mind (thus difficult to apply for a wide-region vulnerability study), it is also considerably less important as long as we employ relatively strong ground motions together with an IM that can outperform a single-period $S_{a}$.

So, which IM should we select for this role? Remarkably, $S_{a}(1 \mathrm{sec})$ seems to have the best performance in terms of the sufficiency among the considered IMs, at least for the No0 12story index building. But is this an indication that we should indeed adopt it? The answer is definitely no, since, as discussed earlier, this is actually a misleading outcome that should be viewed in conjunction with the unsatisfactory efficiency performance of this IM. The latter resulted in highly scattered IM|EDP data in which the linear regression had difficulties finding the significance of $M_{w}$ or $\varepsilon\left(T_{1}\right)$. Instead, $S_{a g m}\left(T_{\mathrm{i}}\right)_{5}$ was found to offer consistently high sufficiency across the board, which combined with its excellent efficiency makes it the best candidate for use with our index buildings. It is also quite reassuring to note that performance of such compound IMs combining several periods does not degrade significantly with a less optimal selection of periods, something also noted by Vamvatsikos and Cornell [20] in a different context. Thus, in general, use of $S_{a g m}\left(T_{\mathrm{i}}\right)_{5}$ can be recommended for assessing the vulnerability of any set of regular index buildings that are not subject to near-source directivity or soft soil issues (although evidence has already been offered in favor of using similar IMs even for pulsive records [24]). Nevertheless, more work is needed to further confirm and extend the applicability of these findings.

\section{CONCLUSSIONS}

The selection of an efficient and sufficient IM is an important task towards developing analytical vulnerability curves and consequently assessing the seismic losses for a building class. It is a choice that can substantially improve or downgrade the results of an otherwise well-executed study. It has been demonstrated that a successful IM might be formed by specifying an appropriate period range that includes periods both above and below the mean first-mode period and combines the associated spectral acceleration values via the geometric mean. In particular, an IM that uses five such periods ranging from the mean second-mode period to twice the mean first-mode period was found to perform best in terms of efficiency and sufficiency across the entire practical range of peak floor acceleration and interstory drift values at every floor and story of both lowrise and highrise structures. Hence, its use is strongly recommended for class vulnerability studies, but also for any kind of performance assessment involving nonlinear dynamic analysis, either for single structures or building ensembles. Nevertheless, by all means, the selection of an efficient and sufficient IM remains an open research area where the last word has not yet been said; future research is expected to offer further insights into what constitutes a good IM and how far it can remove the need for rigorous ground motion selection.

\section{ACKNOWLEDGEMENT}

Financial support was provided by the GEM Foundation through the GEM Vulnerability Consortium, the EU Research Executive Agency via the Marie Curie Continuing Integration Grant No. PCIG09-GA-2011-293855, and Greece and the European Union (European Social 
Fund) through the Operational Program "Human Resources Development" of the National Strategic Framework (NSRF) 2007-2013.

\section{REFERENCES}

1. Aslani H, Miranda E. Probabilistic earthquake loss estimation and loss disaggregation in buildings. The John A. Blume Earthquake Engineering Center, Report No. 157, Stanford, 2005.

2. Fib. Probabilistic performance-based seismic design, fib Bulletin 68, Technical Report. International Federation of Structural Concrete, Lausanne, Switzerland, 2012.

3. Fragiadakis M, Vamvatsikos D, Karlaftis MG, Lagaros ND, Papadrakakis M. Seismic assessment of structures and lifelines. Journal of Sound and Vibration 2015, 334: 2956.

4. Cornell CA. Engineering seismic risk analysis. Bulletin of the Seismological Society of America 1968, 58(5):1583-1606.

5. Luco N, Cornell CA. Structure-specific scalar intensity measures for near-source and ordinary earthquake ground motions. Earthquake Spectra 2007, 23(2): 357-392.

6. Cornell CA, Krawinkler H. Progress and challenges in seismic performance assessment. PEER Center News 2000, 3(2).

7. Baker JW, Cornell CA. A vector-valued ground motion intensity measure consisting of spectral acceleration and epsilon. Earthquake Engineering and Structural Dynamics 2005, 34(10): 1193-1217.

8. Abrahamson NA, Silva WJ. Empirical response spectral attenuation relations for shallow crustal earthquakes. Seismological Research Letters 1997, 68(1): 94-127.

9. Baker JW, Cornell CA. Spectral shape, epsilon and record selection. Earthquake Engineering and Structural Dynamics 2006, 35(9):1077-1095.

10. Iervolino I, De Luca F, Cosenza E. Spectral shape-based assessment of SDOF nonlinear response to real, adjusted and artificial accelerograms. Engineering Structures 2010, 32(9): 2776-2792.

11. Katsanos EI, Sextos AG. ISSARS: An integrated software environment for structurespecific earthquake ground motion selection. Advances in Engineering Software 2013, 58:70-85.

12. Jayaram N, Lin T, Baker JW. A computationally efficient ground-motion selection algorithm for matching a target response spectrum mean and variance. Earthquake Spectra 2011, 27(3): 797-815.

13. Bradley BA, Dhakal RP, MacRae GA, Cubrinovski M. Prediction of spatially distributed seismic demands in specific structures: Ground motion and structural response. Earthquake Engineering and Structural Dynamics 2010, 39(5): 501-520.

14. Vamvatsikos D, Cornell CA. Incremental dynamic analysis. Earthquake Engineering and Structural Dynamics 2002, 31(3):491-514.

15. FEMA. Seismic performance assessment of buildings, FEMA P-58-1. Applied Technology Council for the Federal Emergency Management Agency, Washington, DC, 2012. 
16. FEMA. Quantification of building seismic performance factors, FEMA P695. Applied Technology Council for the Federal Emergency Management Agency, Washington, DC, 2009.

17. PEER. PEER NGA Database. Pacific Earthquake Engineering Research Center, University of California, Berkeley, California, 2006. http://peer.berkeley.edu/nga/.

18. Luco N, Bazzurro P. Does amplitude scaling of ground motion records result in biased nonlinear structural drift responses? Earthquake Engineering and Structural Dynamics 2007, 36(13): 1813-1835.

19. Cordova PP, Deierlein GG, Mehanny SS, Cornell CA. Development of a twoparameter seismic intensity measure and probabilistic assessment procedure. Proceedings of the $2^{\text {nd }}$ US-Japan Workshop on Performance-based Earthquake Engineering Methodology for RC Building Structures, Sapporo, Hokkaido, 2000.

20. Vamvatsikos D, Cornell CA. Developing efficient scalar and vector intensity measures for IDA capacity estimation by incorporating elastic spectral shape information. Earthquake Engineering and Structural Dynamics 2005, 34(13): 1573-1600.

21. Bianchini M, Diotallevi P, Baker JW. Prediction of Inelastic Structural Response Using an Average of Spectral Accelerations. Proceedings of the $10^{\text {th }}$ International Conference on Structural Safety and Reliability (ICOSSAR09), Osaka, Japan, 2009.

22. Tsantaki S, Adam C. Collapse capacity spectra based on an improved intensity measure. Proceedings of the $4^{\text {th }}$ ECCOMAS Thematic Conference on Computational Methods in Structural Dynamics and Earthquake Engineering (COMPDYN 2013), Kos, Greece, 2013.

23. Shakib H, Pirizadeh M. Probabilistic seismic performance assessment of setback buildings under bidirectional excitation. Journal of Structural Engineering (ASCE) 2014, 140(2): doi: 10.1061/(ASCE)ST.1943-541X.0000835

24. Bojorquez E, Iervolino I. Spectral shape proxies and nonlinear structural response. Soil Dynamics and Earthquake Engineering 2011, 31(7):996-1008.

25. Modica A, Stafford PJ. Vector fragility surfaces for reinforced concrete frames in Europe. Bulletin of Earthquake Engineering 2014, 12(4):1725-1753.

26. Baker JW, Cornell CA. Which spectral acceleration are you using? Earthquake Spectra 2006, 22(2):293-312.

27. Reitherman R, Cobeen K. Design documentation of woodframe project index buildings. Publication W-29, Consortium of Universities for Research in Earthquake Engineering, Richmond, CA, 2003.

28. Porter K, Cho I. Characterizing a building class via key features and index buildings for class-level vulnerability functions. Proceedings of the $11^{\text {th }}$ International Conference on Structural Safety \& Reliability (ICOSSAR), Columbia University, New York, NY, 2013.

29. Muthukumar S. The application of advanced inventory techniques in urban inventory data development to earthquake risk modeling and mitigation in Mid-America, $P h D$ thesis, Georgia Institute of Technology, 2008.

30. Kazantzi AK, Vamvatsikos D, Porter K, Cho, I. Developing analytical vulnerability curves for Western US highrise RC frame buildings. Global Vulnerability Consortium, 2014. Available from: www.nexus.globalquakemodel.org/gem-vulnerability/posts/. 
31. Ching JY, Porter KA, Beck JL. Propagating uncertainties for loss estimation in performance-based earthquake engineering using moment matching. Structure and Infrastructure Engineering 2009, 5(3):245-262.

32. Haselton CB, Liel AB, Deierlein GG, Dean BS, Chou JH. Seismic collapse safety of reinforced concrete buildings. I: Assessment of ductile moment frames. Journal of Structural Engineering 2011, 137(4):481-491.

33. D'Ayala D, Meslem A, Vamvatsikos D, Porter K, Rossetto T, Crowley H, Silva V. Guidelines for analytical vulnerability assessment of low/mid-rise buildings Methodology. Vulnerability Global Component project, 2014.

34. NIST. Evaluation of the FEMA P-695 methodology for quantification of building seismic performance factors, Report No. NIST GCR 10-917-8. Prepared for the US National Institute of Standards and Technology by the NEHRP Consultants Joint Venture, Gaithersburg, MD, 2010.

35. Porter K, Farokhnia K, Vamvatsikos D, Cho I. Analytical derivation of seismic vulnerability functions for highrise buildings. Global Vulnerability Consortium, 2014. Available from: www.nexus.globalquakemodel.org/gem-vulnerability/posts/.

36. McKenna F, Fenves G, Jeremic B, Scott M. Open system for earthquake engineering simulation, 2000. <http://opensees.berkeley.edu> (Jan., 2014).

37. Panagiotakos TB, Fardis MN. Deformations of reinforced concrete members at yielding and ultimate. ACI Structural Journal 2001, 98(2): 135-148.

38. Lignos DG, Krawinkler H. Deterioration modeling of steel components in support of collapse prediction of steel moment frames under earthquake loading. Journal of Structural Engineering (ASCE) 2011, 137(11): 1291-1302.

39. Tothong P, Luco N. Probabilistic seismic demand analysis using advanced ground motion intensity measures. Earthquake Engineering and Structural Dynamics 2007, 36(13): 1837-1860.

40. Dawid AP. Conditional independence in statistical theory. Journal of the Royal Statistical Society 1979, 41(1): 1-31.

41. Vamvatsikos D, Cornell CA. Applied incremental dynamic analysis. Earthquake Spectra 2004, 20(2): 523-553.

42. Vamvatsikos D, Cornell CA. Direct estimation of the seismic demand and capacity of MDOF systems through Incremental Dynamic Analysis of an SDOF approximation. ASCE Journal of Structural Engineering 2005, 131(4): 589-599.

43. Nuzzo R. Statistical errors. Nature 2014, 506: 150-152. 